\title{
Micromechanical testing of unirradiated and helium ion irradiated SA508 reactor pressure vessel steels: nanoindentation vs in-situ microtensile testing
}

\author{
C. Gasparrini ${ }^{1, \dagger}$, A. $\mathrm{Xu}^{2,3}$, K. Short ${ }^{2}$, T. Wei ${ }^{2}$, J. Davis ${ }^{2}$, T. Palmer ${ }^{2}$, D. Bhattacharyya ${ }^{2,3}$, L.Edwards ${ }^{2}$, \\ M.R.Wenman ${ }^{1}$ \\ ${ }^{1}$ Department of Materials \& Centre for Nuclear Engineering, Imperial College London, London, SW7 2AZ, UK \\ ${ }^{2}$ Australian Nuclear Science and Technology Organisation, Kirrawee DC, Sydney, NSW 2232, Australia \\ ${ }^{3}$ School of Materials Science and Engineering, University of New South Wales, Sydney, New South Wales, 2052, \\ Australia
}

\begin{abstract}
In this paper, microtensile testing is demonstrated to be a viable technique for measuring irradiation hardening and reduction of ductility of ion irradiated hot isostatic pressed SA508 ferritic/bainitic steel. Ion irradiation with $\mathrm{He}^{2+}$ was used as a surrogate for neutron irradiation to reach a damage level of 0.6 dpa (Kinchin-Pease). The mechanical properties of four unirradiated microtensile steel specimens were measured and compared to the bulk properties: when averaged the $0.2 \%$ proof stress was $501.6 \pm 56.0$ $\mathrm{MPa}$, in good agreement with the macrotensile $0.2 \%$ proof stress of $456.2 \pm 1.7 \mathrm{MPa}$. On the basis of the agreement between microtensile and standard tensile $0.2 \%$ proof stress in the unirradiated material, it was possible to directly measure irradiation induced hardening from ion irradiation performed with $\mathrm{He}^{2+}$ ions to a dose of $0.6 \mathrm{dpa}$. Microtensile testing of the ion irradiated steel revealed an increase in $0.2 \%$ proof stress of approximately $730 \mathrm{MPa}$. The irradiation hardening measured by nanoindentation was $3.22 \pm 0.29 \mathrm{GPa}$. Irradiation hardening was higher than that previously observed in neutron irradiated low alloy steels exposed to similar doses at low temperatures $\left(<100^{\circ} \mathrm{C}\right)$. The reason for the higher hardening was related to the presence of fine helium bubbles implanted in the irradiated layer that, alone, was calculated to produce a $707 \pm 99 \mathrm{MPa}$ increase in yield stress.
\end{abstract}

\section{Keywords}

In situ micro-mechanical testing, Irradiation hardening, Nanoindentation, Reactor pressure vessel steels 


\section{Introduction}

Recently there has been a considerable desire to extend the lifetime of the world's pressurized water reactor (PWR) fleet from 40 to 60 or possibly 80 years[1]. The continued safe operation of these reactors is intrinsically linked to the structural integrity of the steel used for the reactor pressure vessel (RPV). Matrix damage and solute clustering induced by neutron irradiation are considered to be among the main causes of embrittlement of RPV steel. Intensive research has been ongoing to investigate embrittlement mechanisms of low alloy ferritic RPV steels in the past 40 years[2-8]. Testing neutron irradiated materials can take a long time and is very expensive, hence alternative methods to irradiate materials have been exploited recently.

Ion irradiation[9] is widely used to simulate the damaging effects observed on neutron irradiated materials such as voids, bubbles, dislocation loops[10,11], radiation-induced[11] or -enhanced solute segregation[10],[12], precipitate dissolution[13] and degradation of mechanical properties[14] as it has the advantage of inducing high doses in short times (days instead of years) without unduly activating the samples[15,16]. The irradiated volume of ion implanted material is, however, limited as the penetration depth of light ions with modest energies (several MeV) is of the order of tens of microns[16]. Small-scale mechanical techniques[17] that enable characterization of small interaction volumes are therefore needed to obtain mechanical properties data from ion irradiated materials. Reducing the size of samples to non-standardized sizes is not a novel approach in the nuclear materials field as this has been implemented for decades[18]. The results from miniature tensile, compact tension and sub-sized Charpy V-notch (CVN) have been used in various irradiation programmes with fairly good agreement with larger specimens[18]. The further recent development of micromechanical testing, brought about by focused ion beam (FIB) milling, allows researchers to evaluate mechanical properties at a micro scale reducing considerably sample volumes: the gauge length of each specimen being only a few microns instead of millimetres. The manufacturing of small volume samples is of great interest in the nuclear research field as it directly reduces samples activity aiding handling procedures.

Micromechanical testing is still a relatively novel technique and microtensile specimens have been manufactured using gallium FIB [19-29] broad ion milling on protective stencil masks [30,31] xenon 
FIB [32] and film deposition and lithographic structuring followed by local etching[33]. Microtensile testing has been applied to ion irradiated materials and previous work considers ion irradiated nickel[27-29] stainless steel[21] and low alloy steel[32].

This work presents in-situ micro tensile testing together with nanoindentation of a novel manufactured RPV steel: hot isostatic pressed (HIP) SA508 grade 3 steel. Both techniques were applied to unirradiated and helium ion irradiated samples. The aim of this research was to investigate the capability of using micromechanical testing to measure irradiation hardening and embrittlement of RPV steels. Mechanical properties obtained using in-situ microtensile testing were compared with standard tensile testing and the widely used nanoindentation technique providing a benchmark for micromechanical testing of RPV steels. Microtensile testing was able to directly measure ion irradiation hardening and embrittlement, something that it was not possible to achieve with other techniques such as nanoindentation as it will be here discussed. Tests were performed under the same conditions on unirradiated and $5 \mathrm{MeV} \mathrm{He}^{2+}$ ions irradiated specimens at room temperature to a dose of 0.6 dpa (Kinchin-Pease) using a 2 MV tandem accelerator with energy degrader.

\section{$2 \quad$ Materials and methods}

\subsection{Sample preparation and characterisation}

The SA508 grade 3 steel used for this work was provided by Rolls-Royce, the chemical analysis of the steel sample after consolidation during the HIP process is given in Table 1. The material was sliced into samples with dimensions of $5 \mathrm{~mm} \times 5 \mathrm{~mm} \times 2 \mathrm{~mm}$. These were initially ground with Struers® $\mathrm{SiC}$ paper grit $800,1200,2000$ and 4000 followed by a $3 \mu \mathrm{m}$ and $1 \mu \mathrm{m}$ polishing stage using diamond solution applied on a Struers MD Nap cloth and polished to electron backscatter diffraction (EBSD) finish using colloidal silica. Fiducial markers were applied on the polished surface to highlight the region of interest prior to taking EBSD maps. To characterise the bainitic and ferritic phases, EBSD was performed using a Zeiss ${ }^{\circledR}$ UltraPlus ${ }^{\mathrm{TM}}$ scanning electron microscope (SEM) with an Oxford Instrument NordlyS EBSD detector. The sample was tilted to $70^{\circ}$ and a voltage of $20 \mathrm{kV}$ was used for EBSD pattern acquisition. An EBSD step size of $50 \mathrm{~nm}$ was used to analyse the surface of microtensile 
specimens, while a step size of $230 \mathrm{~nm}$ was used to analyse the sample surface pre and post indentation. EBSD patterns were plotted and analysed using the software Channel $5^{\mathrm{TM}}$ with modules called Tango ${ }^{\mathrm{TM}}$ (mapping) and Mambo ${ }^{\mathrm{TM}}$ (pole figure) from Oxford Instruments ${ }^{\circledR} \mathrm{HKL}^{\mathrm{TM}}$, UK. Samples were stored in a desiccator containing silica gel prior to irradiation and during characterisation.

Table 1 Chemical composition of tested SA508 HIP low alloy steel in wt\% (iron, Fe, balanced), chemical measurements were made on consolidated powder.

\begin{tabular}{|ccccccccccccc|}
\hline $\mathrm{C}$ & $\mathrm{Mn}$ & $\mathrm{P}$ & $\mathrm{S}$ & $\mathrm{Si}$ & $\mathrm{Ni}$ & $\mathrm{Cr}$ & $\mathrm{Mo}$ & $\mathrm{V}$ & $\mathrm{Cu}$ & $\mathrm{Al}$ & $\mathrm{N}$ & $\mathrm{O}$ \\
\hline 0.16 & 1.24 & 0.012 & 0.006 & 0.21 & 0.86 & 0.1 & 0.51 & $<0.01$ & 0.03 & 0.02 & 0.018 & 0.014 \\
& & & & & & & & & & & & \\
\hline
\end{tabular}

\subsection{Ion irradiation}

A sample polished to EBSD finish was irradiated by $5 \mathrm{MeV} \mathrm{He}^{2+}$ ions, at room temperature, to a damage level of 0.6 dpa using the 2 MV STAR tandem accelerator equipped with an energy degrader wheel at the Australia's Nuclear Science and Technology Organisation (ANSTO). SRIM/TRIM software[34] was used to calculate the fluence (ions $\mathrm{cm}^{-2}$ ) required to induce a particular dose in the HIP SA508 grade 3 sample using $\mathrm{He}^{2+}$. The displacement threshold energy used for the SRIM/TRIM simulation was set to $40 \mathrm{eV}$ and the damage calculations were done using the "quick" Kinchin and Pease option as suggested by Stoller et al.[35] for iron and iron alloys. The energy degrader wheel was used to produce a relatively even through depth irradiation damage in the material by attenuating and spreading the $\mathrm{He}$ ion energies[36,37]. In this way, the damage region is enlarged as multiple Bragg peaks are positioned through a range of depths. The position of each Bragg peak in the sample as predicted by SRIM/TRIM is shown in Figure 1a. The resultant high fluence of $5.4 \times 10^{17}$ ions $\mathrm{cm}^{-2}$ enabled a dose of $\sim 0.6 \mathrm{dpa}$ in a reasonable amount of accelerator beam time ( $\approx 4$ days). The dose of $\sim 0.6$ dpa Kinchin-Pease was chosen as it is comparable to the dose received by RPV steels after approximately 160 years operation, which is well beyond the 80 years extended lifetime now considered.

The degrader wheel was made up of 20 aluminium foils with thicknesses from $0.8 \mu \mathrm{m}$ to $20 \mu \mathrm{m}$ and the predicted dpa and helium concentration estimated using SRIM/TRIM software is shown in Figure 1b and c. The dpa values were estimated at a depth of $5 \mu \mathrm{m}$. The averaged dpa is highlighted with a dashed 
line in Figure 1b, the averaged helium concentration calculated from helium ion distribution table from SRIM/TRIM is shown in Figure 1c.

The principal advantage of using the degrader wheel is the relatively flat damage profile in the region from where the microtensile specimens were fabricated (between $2-8 \mu \mathrm{m}$ from the top surface), whilst the main drawback of using the degrader wheel and $\mathrm{He}^{2+}$ irradiation was the deposition of helium bubbles in the samples[38,39].

a)

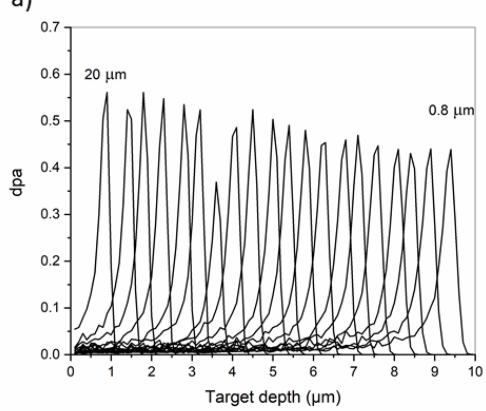

b)

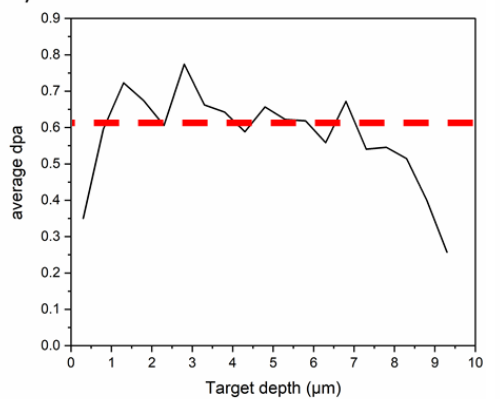

c)

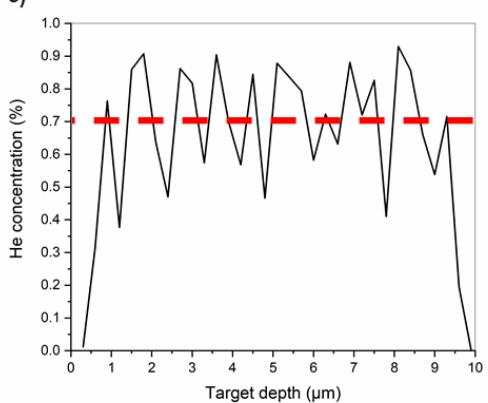

Figure 1 Dpa and helium concentration estimated using SRIM/TRIM software after irradiation to a fluence of $5.4 \times 10^{17}$ ion $\mathrm{cm}^{-2}(\sim 0.6 \mathrm{dpa})$ : a) displacement damage dose profiles obtained from the action of the energy degrader wheel fitted with several aluminium foils: two foils thicknesses are highlighted; b) average damage profile obtained using the degrader wheel; c) average helium concentration using the degrader wheel.

\subsection{Nanoindentation}

Nanoindentation was performed in both normal mode and in continuous stiffness mode (CSM, frequency set to $45 \mathrm{~Hz}$ ) perpendicular to the top surface on as-received and ion irradiated samples. The hardness data were obtained using a MTS Nanoindenter G300 with a Berkovich tip with a Poisson's ratio of 0.3 and displacement rate of $0.5 \mathrm{~s}^{-1}$. To characterise the hardness of the ferritic and bainitic phases, EBSD maps were acquired on two areas highlighted by fiducial markers prior to nanoindentation. A total of 128 indents were made in the unirradiated material: zone 1 included 48 indents in a $6 \times 8$ array, while zone 2 had a total of 80 indents in a $10 \times 8$ array. Indents were positioned $30 \mu \mathrm{m}$ apart and tested under load control using a maximum of $6 \mathrm{gF}$, while the maximum displacement was $\sim 1 \mu \mathrm{m}$. 80 indents in a $10 \times 8$ array in CSM mode were positioned $100 \mu \mathrm{m}$ apart and tests were performed in displacement control to a depth of $\sim 2 \mu \mathrm{m}$ in both as-received and ion irradiated steels. Surface approach velocity and harmonic displacement was $10 \mathrm{~nm} \mathrm{~s}^{-1}$ and $4 \mathrm{~nm}$. 


\subsection{Microtensile testing}

A Zeiss ${ }^{\circledR}$ Auriga 60 Crossbeam ${ }^{\mathrm{TM}}$ Ga FIB instrument was used to fabricate micro tensile specimens with approximate gauge dimensions of length $=17 \mu \mathrm{m} \times$ width $=5 \mu \mathrm{m} \times$ thickness $=5 \mu \mathrm{m}$. Details of the method by which these microtensile specimens have been manufactured can be found in Reichardt et al.[27] and Xu et al.[28]. In-situ microtensile testing was performed in a Zeiss ${ }^{\circledR}$ UltraPlus ${ }^{\mathrm{TM}}$ SEM using a micro-test rig (MTR-3) developed by MicroTesting Solutions ${ }^{\circledR}$ (Hilliard, U.S.A.). Tests were performed under displacement control at a rate of $20 \mathrm{~nm} \mathrm{~s}^{-1}$ (which corresponds to an approximate strain rate of $0.0012 \mathrm{~s}^{-1}$ ), details of the test procedure can be found in Reichardt et al.[27]. The average stressstrain data were obtained by linearly interpolating the stress of each test at a specific strain and by calculating the mean between all tests.

\subsection{Transmission electron microscopy}

The same Zeiss ${ }^{\circledR}$ Auriga 60 Crossbeam $^{\mathrm{TM}}$ FIB was used to manufacture transmission electron microscope (TEM) samples. Platinum deposition was used to protect the lamella, which was cut perpendicular to the ion implanted top surface, thinning of the TEM lamella was made using $30 \mathrm{kV}$ and a current of $240 \mathrm{pA}$ and $120 \mathrm{pA}$, followed by successive polishing stages at accelerating voltage of 15 $\mathrm{kV}$ using a current of $80 \mathrm{pA}, 5 \mathrm{kV}$ using a current of $20 \mathrm{pA}$ and finally $2 \mathrm{kV}$ and current of $20 \mathrm{pA}$. TEM was performed on a JEOL $® 2200 \mathrm{FS}^{\mathrm{TM}}$ at $\mathrm{ANSTO}$ and on a JEOL $®$ JEM $2100 \mathrm{~F}^{\mathrm{TM}}$ at Imperial College London using a $200 \mathrm{keV}$ accelerating voltage. Underfocus and overfocus conditions were used to image defects such as bubbles/voids in the TEM sample in bright field mode. Using underfocus condition these defects appeared white surrounded by dark fringes, using overfocus condition the same defects appeared dark surrounded by white fringes[40,41]. Bubble/void size and number within a certain region were measured using Fiji ImageJ software[42,43] Analyse Particles plugin. The helium bubble size at 0 defocus was extrapolated from the bubbles diameter measurements taken at $\pm 1000 \mathrm{~nm}$ and $\pm 2000 \mathrm{~nm}$ defocus assuming a linear relationship. Energy Filtered TEM (EFTEM) thickness maps were acquired using a Gatan Quantum image filter (GIF) system on the same region bubble/void size and number were measured. The thickness measured by EFTEM was used to calculate the sample volume to obtain the bubbles/void number density $\left(\mathrm{nm}^{-3}\right)$. 


\section{Results}

\subsection{Unirradiated samples}

EBSD maps of the polished sample surface revealed the microstructure of the HIP SA508 grade 3 steel to be a mixture of ferrite and bainite as shown by the band contrast map[44] and the 1 degree grain boundary map in Figure 2a and b, where the bainitic phase contains a high level of local misorientation, highlighted by a high density of small angle grain boundaries[45]. The hardness of the unirradiated samples was assessed by nanoindentation prior to microtensile testing. In order to estimate both the overall hardness of the alloy and the difference in hardness of the ferritic and bainitic phases, nanoindentation was performed in areas that had already been mapped by EBSD (see Figure $2 b$ ). The indents' location on the sample surface can be observed in the EBSD map in Figure 2c performed after nanoindentation. The hardness of the bainitic and ferritic phases was measured by analysing hardness data at maximum load (displacement of approximately $1060 \mathrm{~nm}$ ) of indents that were positioned entirely within bainitic or ferritic grains. The average hardness was $2.36 \pm 0.21 \mathrm{GPa}$, where the hardness of bainitic grains was $2.49 \pm 0.13 \mathrm{GPa}$ and that of ferritic grains was $2.05 \pm 0.14 \mathrm{GPa}$ considering one standard deviation. This is shown in Figure 2d. 
a)

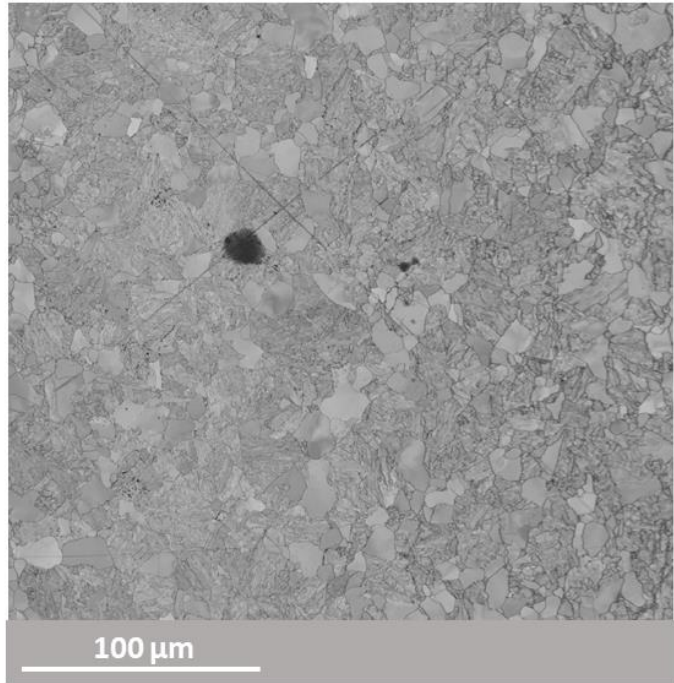

c)

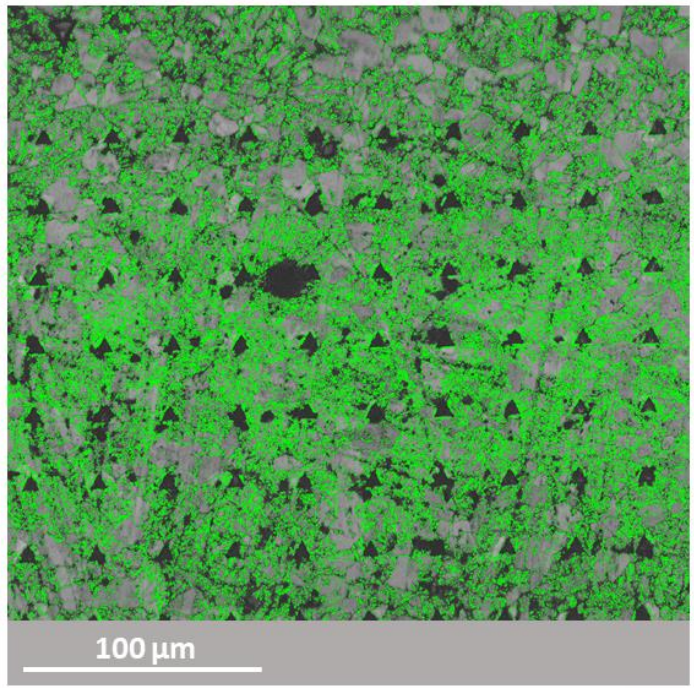

b)

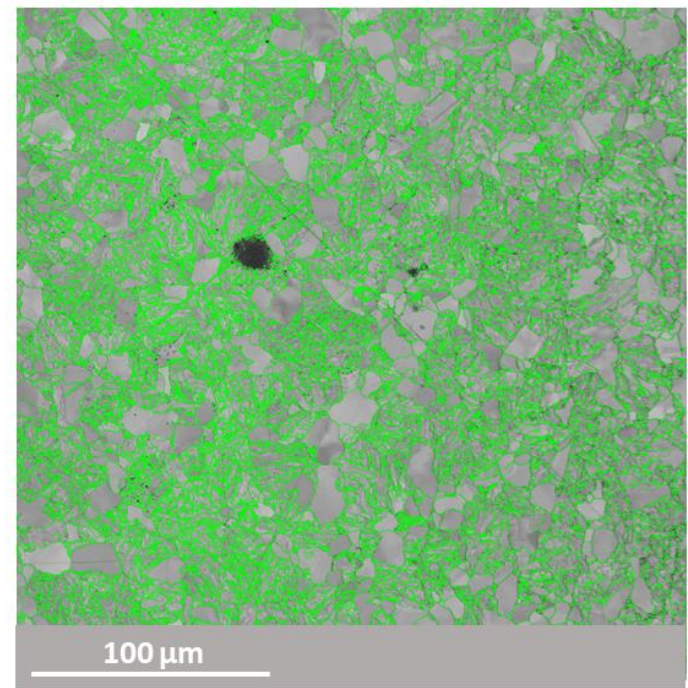

d)

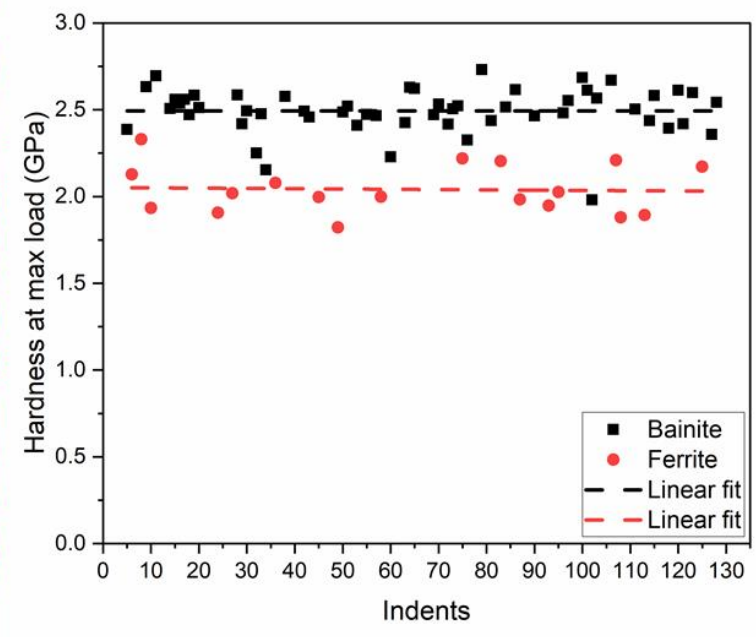

Figure 2 a) EBSD band contrast map of a HIP SA508 grade 3 unirradiated steel sample prior to nanoindentation (zone 2); b) 1 degree grain boundary map showing the presence of the bainitic phase (high level of misorientation) of the region in a); c) 1 degree grain boundary map shown in b) after indentation showing the location of the indents and d) nanohardness at maximum load of indents that were situated within a fully bainitic or fully ferritic grains.

The difference in hardness of the bainitic and ferritic phases was $0.44 \pm 0.15 \mathrm{GPa}$ at $\sim 1 \mu \mathrm{m}$ depth. Nanoindentation provides an estimate of the material hardness; it is, however, not possible to directly obtain tensile properties such as ultimate tensile stress (UTS) and yield stress[46] from these tests. The tensile properties were measured macroscopically via standard mechanical testing and, independently, by using uniaxial microtensile testing. Four microtensile specimens were FIB prepared from the polished surface of the as-received unirradiated sample. After FIB milling, the top surface was finely polished by FIB for EBSD analysis. EBSD maps were made on each of the top surface gauge lengths 
to assess which phases were present in the samples. The presence of bainitic and ferritic phases were observed using the local misorientation plots in Figure 3. Pole figures for each EBSD map are also shown.
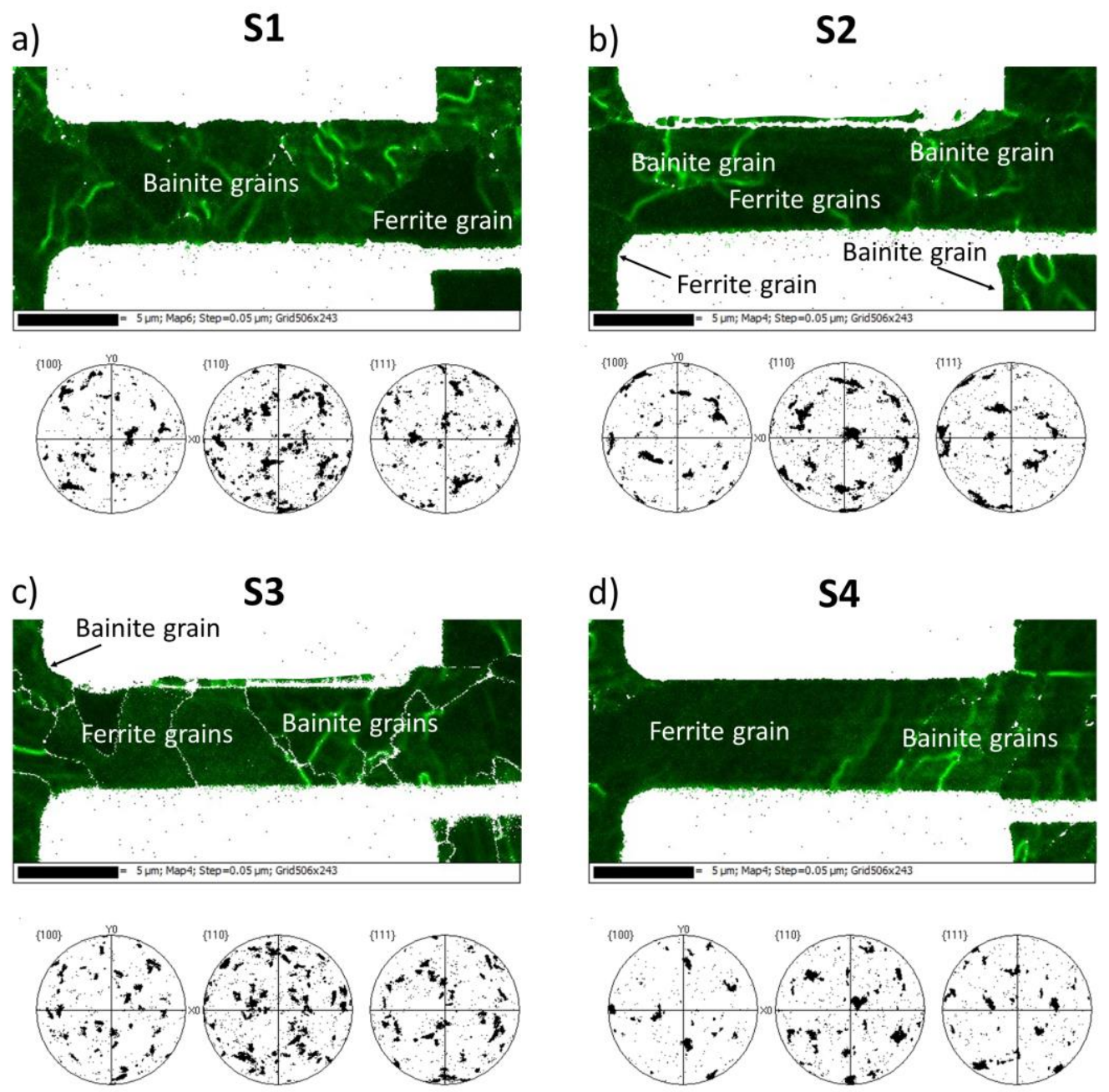

Figure 3 EBSD map showing local misorientation and pole figure of each of the four microtensile specimens. Specimens were labelled S1, S2, S3, S4 and they are respectively shown in a), b), c) and d).

The four microtensile specimens, labelled S1, S2, S3 and S4, contained both ferritic and bainitic phases with the bainitic grains showing evidence of high local misorientation. The dimensions of the gauge section (width and thickness) were estimated from a secondary electron image (SEI) taken at 45 degrees tilt, the approximate measurements are summarised in Table 2. 
Table 2 Microtensile gauge section measurements taken on SEIs at $45^{\circ}$ tilt (width $\times$ thickness).

\begin{tabular}{|cccc|}
\hline $\mathrm{S} 1$ & $\mathrm{~S} 2$ & $\mathrm{~S} 3$ & $\mathrm{~S} 4$ \\
\hline $5.63 \times 5.16 \mu \mathrm{m}^{2}$ & $5.74 \times 4.79 \mu \mathrm{m}^{2}$ & $5.37 \times 5.69 \mu \mathrm{m}^{2}$ & $5.60 \times 4.69 \mu \mathrm{m}^{2}$ \\
\hline
\end{tabular}

Each microtensile specimen was tested in-situ under the same conditions and the stress-strain curve was obtained from the analysis of the SEM images using a Matlab® based digital image correlation code that is supplied with the MTR-3[27] microtesting system. The stress-strain curve from each test was interpolated to obtain a more continuous curve using calibration of the load-displacement curve using the technique according to $\mathrm{Xu}$ et al.[28]. The engineering stress-strain curve for each specimen is presented in Figure 4a.

The stress-strain curves from the four microtensile tests were averaged to enable comparison between the microtensile and macrotensile tests. This procedure may be justified by two observations - (i) all specimens contained both bainitic and ferritic grains, as evident from misorientation maps in Figure 3, resembling bulk-like microstructure, and (ii) it is seen from the overall orientation distributions from the combined pole figures of all the four microtensile samples that they resemble the bulk texture, therefore the range of orientations sampled increases to a more bulk-like distribution, see Figure 4c.

The mean stress strain curve from the four microtensile tests is shown in Figure 4b, where the error bars extend to \pm 1 standard error (SE). The UTS of the unirradiated HIP material measured using standard mechanical testing was $577.8 \pm 2.6 \mathrm{MPa}$ and the $0.2 \%$ proof stress was $456.2 \pm 1.7 \mathrm{MPa}$ considering 1 SE (courtesy of Rolls-Royce). Figure $4 \mathrm{~b}$ shows the UTS of the bulk (standard tensile testing) compared to the UTS obtained with the microtensile testing. It is evident from this plot that the mechanical properties evaluated with standard macroscale testing lies within the confidence interval of the micromechanical test after averaging the stress strain curves of four tensile specimens.

The linear elastic region was well represented by the micro tensile test when comparing the microtensile curve to the standard tensile curve (see Figure 4d). The plastic region, instead, showed some discrepancies as a reduction in the nominal stress was observed at low strains. It has been previously 
reported that post necking strain to failure shape is dependent on gauge section thickness - length aspect ratio in miniature dog-bone specimens[47,48]. Zhao et al.[47] reported that elongation to failure, post necking elongation and strain hardening rate can all increase by reducing gauge length or increase gauge thickness. Previous work done on microtensile testing of martensitic steel by Smith et al.[32] showed similar behaviour of the plastic region to the one reported in Figure 4d. In the work by Smith et al.[32] the microtensile specimens had larger dimensions than the ones used in this work $(1=132 \mu \mathrm{m} \times \mathrm{w}=$ $17.5 \mu \mathrm{m} \times \mathrm{t}=40 \mu \mathrm{m})$, however, the gauge section thickness/gauge length ratio of the microtensile specimens in Smith et al.[32] and this work are both approximately 0.3.

a)

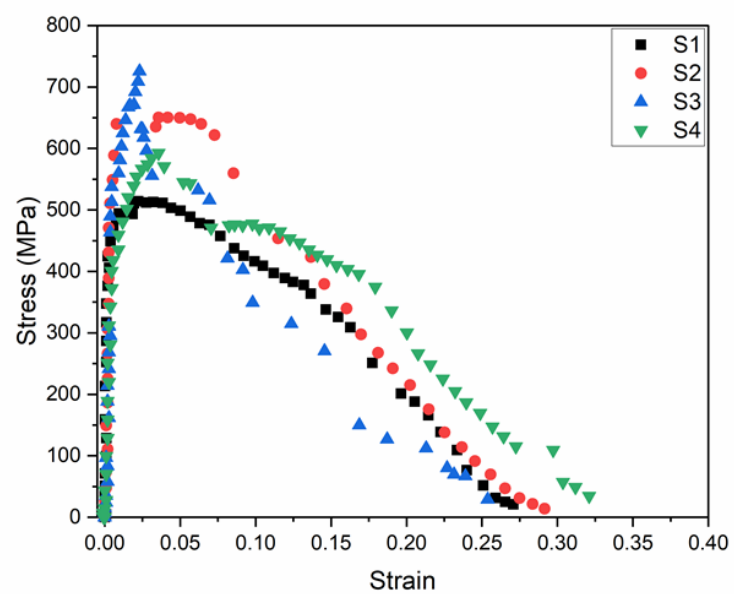

b)

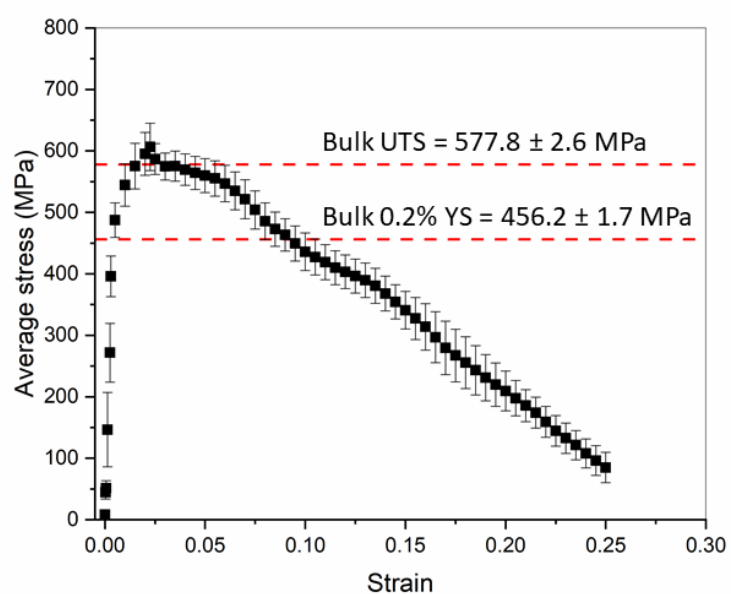

d)

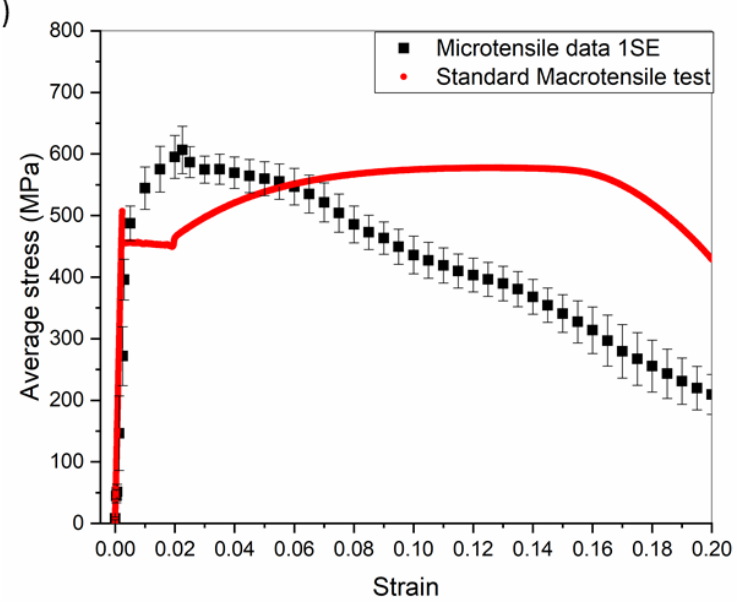

Figure 4 Engineering stress-strain curve for a) each microtensile specimen (S1, S2, S3, S4) tested in the unirradiated sample; b) average stress strain curve obtained after interpolating and averaging the curves seen in a), the dashed lines represent the $0.2 \%$ proof stress and the UTS obtained by standard macro mechanical test, error bars represent $1 \mathrm{SE}$; c) combined pole figure 
representing all grain orientations present in S1, S2, S3 and S4 specimens d) comparison between averaged stress strain curve and the bulk tensile test stress strain curve

\subsection{Ion Irradiated samples}

The same methodology used for unirradiated samples was used to assess the mechanical responses of the ion irradiated HIP RPV steel. The hardening of the samples irradiated to 0.6 dpa was measured via nanoindentation using the CSM method, which meant the change in the hardness of the material with depth could be measured. Figure 5 a shows that the hardness of the irradiated material remained constant with depth showing that the use of the degrader wheel had produced a relatively flat damage profile as predicted by SRIM/TRIM calculations (see Figure $1 \mathrm{~b}$ ). The maximum displacement of the indents was $\approx 2 \mu \mathrm{m}$ and the irradiated region was $10 \mu \mathrm{m}$ deep, therefore the plastic zone due to the indents was located mostly within the irradiated layer. Figure 5 a shows the hardness of unirradiated sample was approximately $3 \mathrm{GPa}$ while the $0.6 \mathrm{dpa}$ ion irradiated samples had a hardness of $6 \mathrm{GPa}$. The difference in hardness between the unirradiated and ion irradiated sample was calculated for each corresponding depth and plotted in Figure 5 b. 
a)

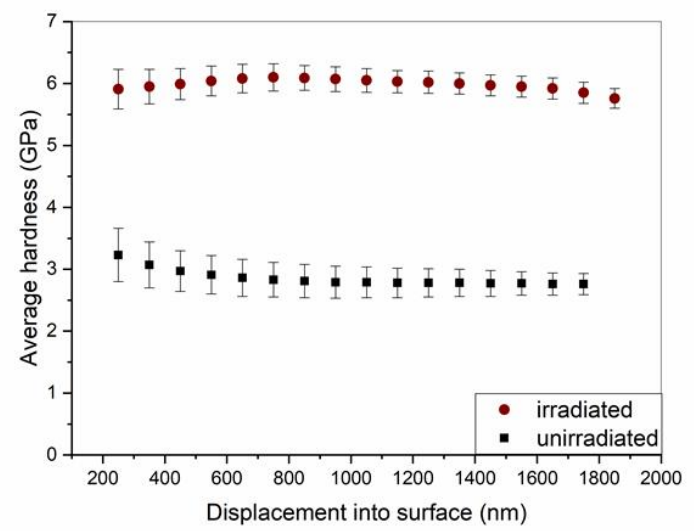

c)

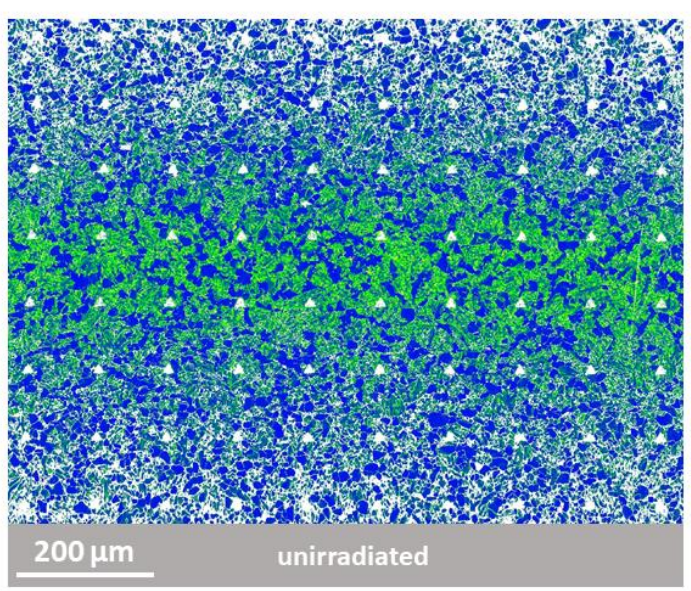

b)

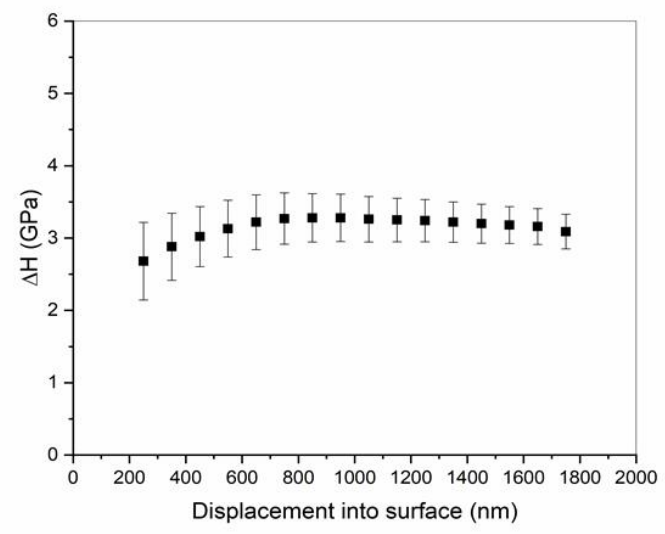

d)

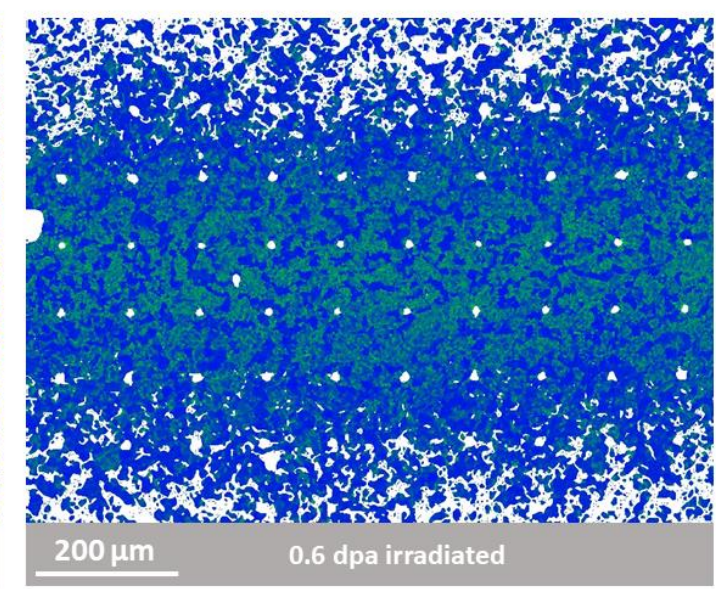

Figure 5 a) Nanoindentation data obtained in CSM mode on the 0.6 dpa helium irradiated sample and unirradiated sample: average hardness versus displacement; b) increase in hardness due to ion irradiation, $\Delta H$, with depth; c) and d) local misorientation EBSD maps after indentation showing the location of the indents analysed in a): the green colour, which results from higher local misorientation (dislocation density) highlights bainitic grains and blue the ferritic grains in the unirradiated sample (shown in c) and ion irradiated sample (shown in d).

Nanoindentation provided unequivocal evidence of the radiation induced hardening of the ion irradiated steel. The hardening behaviour of the two phases, bainite and ferrite, after irradiation was studied by analysing the average hardness with depth of indents that were positioned entirely within bainitic or ferritic grains. This was possible using the information collected from EBSD maps shown in Figure 5c and $d$ (only indents that were positioned on resolved grains were considered). The hardness of the unirradiated bainite and ferrite phases measured by CSM mode was respectively $2.89 \pm 0.19 \mathrm{GPa}$ and $2.69 \pm 0.24$. The hardness of the $0.6 \mathrm{dpa}$ ion irradiated bainite and ferrite phases was respectively 6.08 $\pm 0.34 \mathrm{GPa}$ and $6.03 \pm 0.17 \mathrm{GPa}$ highlighting that both phases reached a similar level of hardness. 
In order to measure radiation induced hardening and embrittlement, microtensile tests were performed.

Microtensile specimens were manufactured using the same method described for the unirradiated sample. The microtensile gauge thickness was approximately $5 \mu \mathrm{m}$, therefore the entire microtensile specimen was machined from within the ion irradiated layer as illustrated in Figure 6.

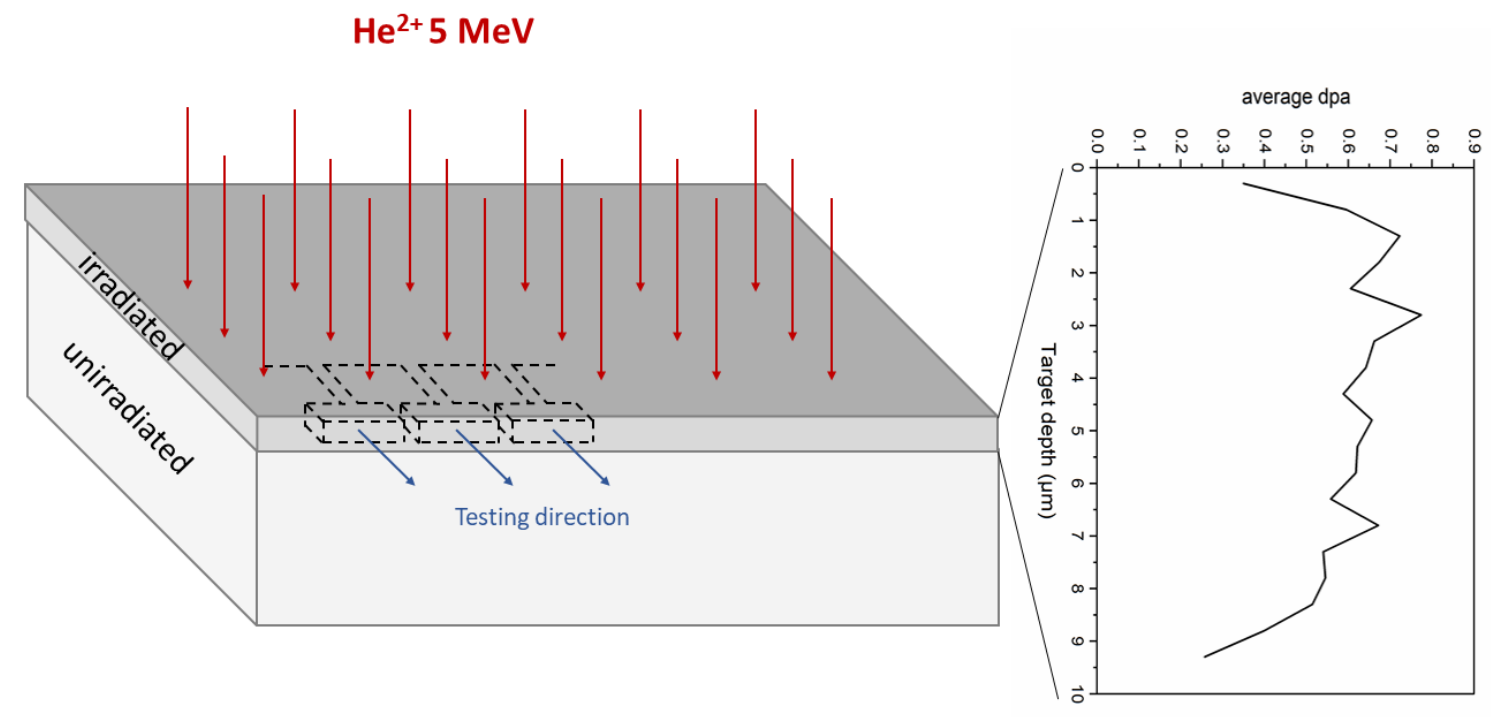

Figure 6 Schematic of the tensile test manufacturing procedure: the microtensile gauge section lies entirely within the $\mathrm{He}^{2+}$ implanted irradiated layer

Three microtensile specimens were FIB prepared from the irradiated layer and the tensile test axis was perpendicular to the ion implantation direction. EBSD mapping was performed on the top surface for each tensile gauge length and the local misorientation maps were plotted to identify bainitic and ferritic grains. These EBSD maps are shown in Figure 7 alongside gauge section pole figures. 
a)
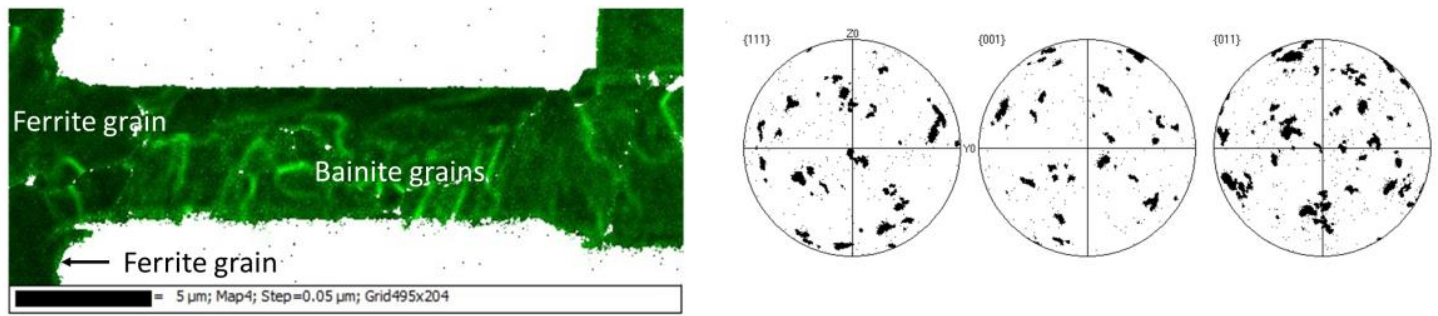

b)

S6
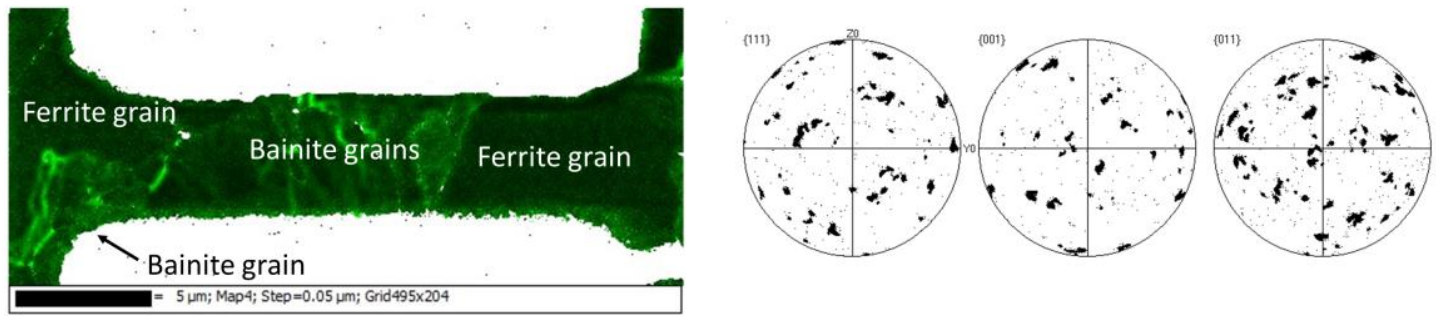

c)

S7
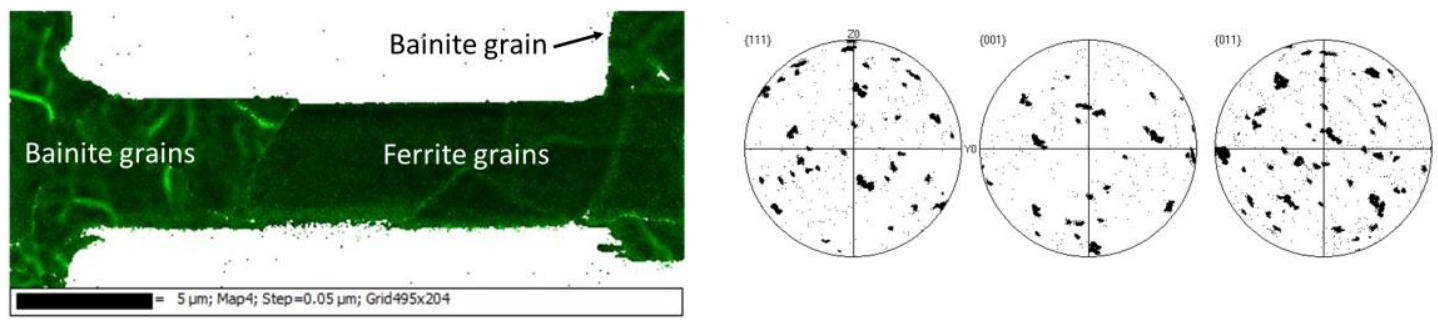

Figure 7 EBSD map showing local misorientation and pole figure of each ion irradiated microtensile specimen. Specimens were labelled as S5, S6, and S7 and they are shown in a), b) and c) respectively.

Similarly to the unirradiated microtensile specimens, the ion irradiated specimens contained both bainitic and ferritic grains. As before, the bainite is highlighted by significant local misorientation within the grain, which corresponds to small angle grain boundaries. The dimensions of the three microtensile gauge sections, which are labelled S5, S6 and S7, are shown in Table 3.

Table 3 Microtensile gauge section measurements made on SEIs at $45^{\circ}$ tilt (width $\times$ thickness).

\begin{tabular}{|ccc|}
\hline S5 & S6 & S7 \\
\hline $4.84 \times 5.95 \mu \mathrm{m}^{2}$ & $4.36 \times 5.79 \mu \mathrm{m}^{2}$ & $4.69 \times 5.63 \mu \mathrm{m}^{2}$ \\
\hline
\end{tabular}

Microtensile testing was performed using the same methodology described for the unirradiated samples.

The individual tests shown in Figure 8a showed significant hardening and reduction in ductility. By 
interpolating the individual stress-strain data for intermediate strain points it was possible to obtain an average stress-strain curve for the irradiated samples (see Figure 8b). The averaged stress-strain plot corresponds to a virtual sample with a combined orientation distribution from all samples, as represented in Figure 8c. Using this method it was possible to directly measure radiation induced hardening and embrittlement by comparing the averaged stress strain curves for the unirradiated and ion irradiated tests as shown in Figure $8 \mathrm{~d}$. The increase in $0.2 \%$ proof test measured by micromechanical testing was $727.7 \pm 72.5 \mathrm{MPa}$.

a)

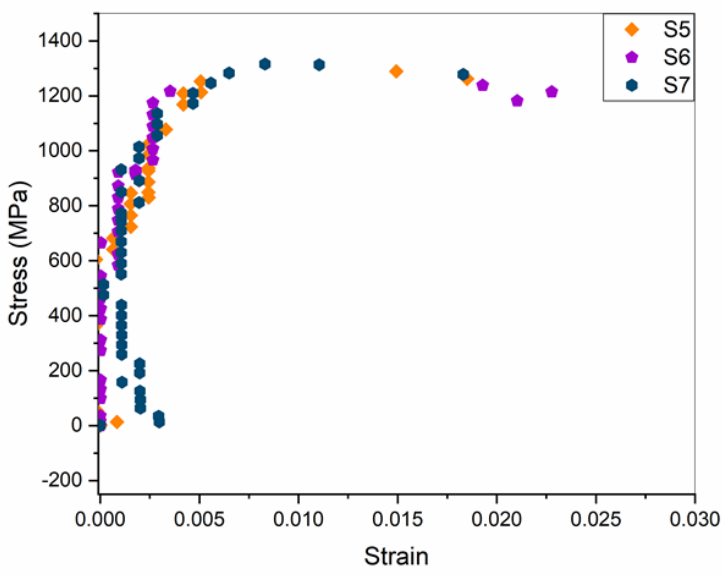

c)

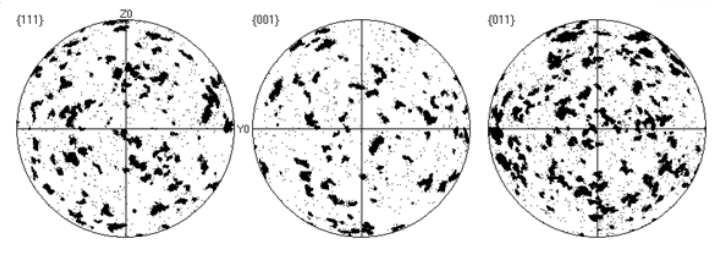

b)

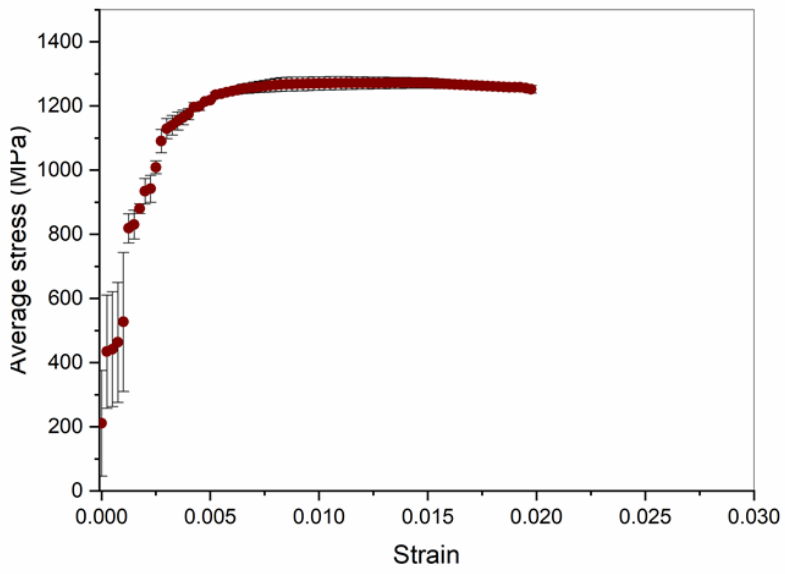

d)

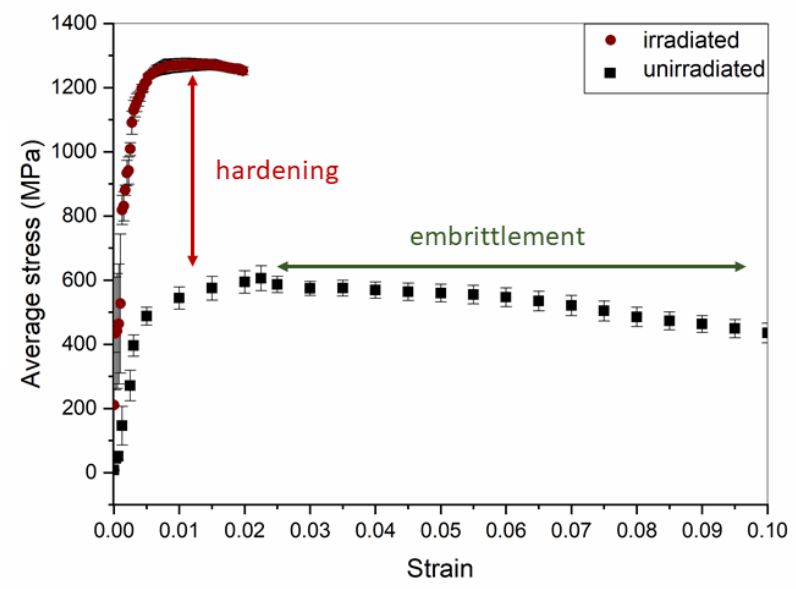

Figure 8 Engineering stress strain curve for a) each individual ion irradiated microtensile specimen (S5, S6, S7) tested; b) average stress strain curve obtained after interpolating and averaging the curves seen in a), error bars represent 1SE; c) overall pole figure representing all orientations present in S5, S6 and S7 specimens; d) comparison between averaged stress strain curve for the unirradiated and irradiated tests

TEM analysis was performed on the unirradiated and irradiated samples to understand the nature and underlying cause of irradiation hardening and embrittlement measured by microtensile testing. 


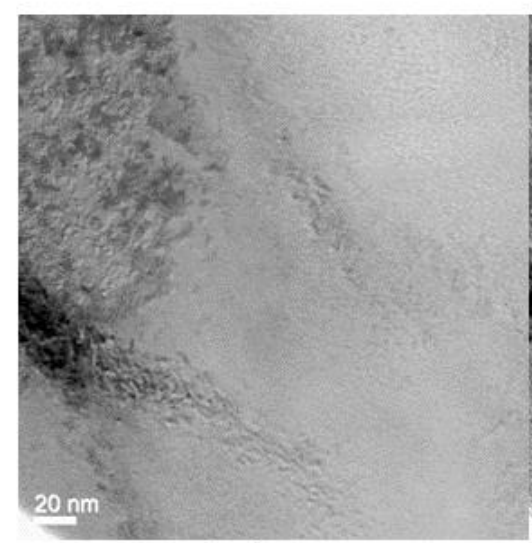

In focus

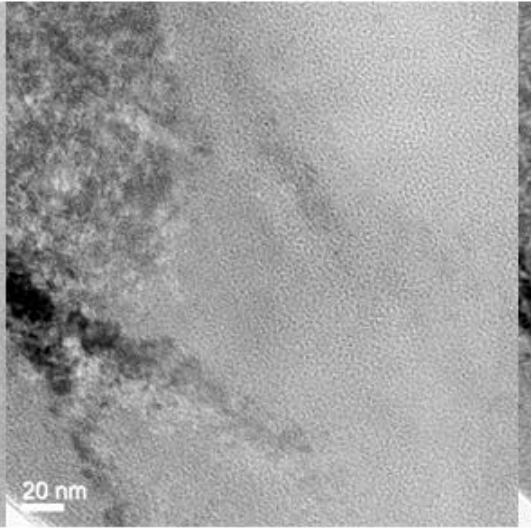

Overfocus $+1000 \mathrm{~nm}$

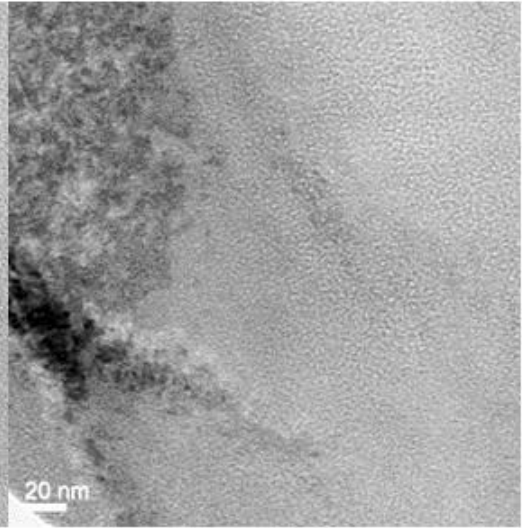

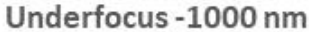

Figure 9 Microstructure of the HIP SA508 steel irradiated to 0.6 dpa at room temperature. The presence of bubbles is highlighted by the characteristic change in Fresnel contrast in the underfocus and overfocus bright field (BF) TEM images

The presence of fine bubbles/voids in the 0.6 dpa irradiated sample was demonstrated by the overfocus and underfocus images in Figure $9 \mathrm{~b}$ and $\mathrm{c}$. The average diameter of these features was $1 \mathrm{~nm} \pm 0.5 \mathrm{~nm}$ (after extrapolation to 0 defocus), the bubbles number density was $2.5-4.5 \times 10^{24} \mathrm{~m}^{-3}$. The presence of helium bubbles was expected at these dpa values in steels[38,39] as the helium concentration was approximately $0.7 \%$ (see Figure 1c) due to the fact that Bragg peaks lay within the ion irradiated layer. Even though the presence of helium could not be chemically mapped within the small features shown in Figure 9, these features were considered helium bubbles as helium is known to be insoluble in most metals[49] and energetically is most favoured to be present in bubbles[49,50]. Previous literature on helium irradiation of steels at room temperature discusses the issue of distinguishing bubbles from cavities of such small size (1-2 nm) [39,51]. Chen, S. et al.[39] called the observed features cavities, Roldán, M. et al.[51] called the observed features nanobubbles.

The contribution from the implanted bubbles to the increase in hardness measured by nanoindentation and microtensile testing was evaluated using the dispersed barrier hardening (DBH) model. The DBH model allows an estimation of the yield stress increment $(\Delta \sigma)$ induced by helium bubbles (shown in Figure $9 \mathrm{~b}$ and $\mathrm{c}$ ) using equation 1 :

$$
\Delta \sigma=\alpha \times \mathrm{M} \times \mu \times \mathrm{b} \times \sqrt{N d}
$$

where $\alpha$ is the obstacle strength and is often considered to be $=0.2$ for helium bubbles in ferritic steels[52] and austenitic steels[53]. $M$ is the Taylor factor and is considered equal to 3.06 for both bcc 
and fcc lattices[54,55], $\mu$ is the shear modulus ( $80 \mathrm{GPa}$ for ferritic steel) and $b$ is the Burgers vector modulus ( $0.2485 \mathrm{~nm}$ in bcc ferrite). $N$ and $d$ are the number density of defects and the average diameter of the bubbles respectively. The increase in yield strength $(\Delta \sigma)$ induced by the presence of helium bubbles in the sample is thus estimated to be $707 \pm 99 \mathrm{MPa}$ after measuring the number density and average diameter of the bubbles in three regions using TEM imaging as shown in Figure 9. The error is associated to the variation of bubble number density measured in three regions and on the uncertainty of the TEM lamella thickness which was estimated to be between $18 \mathrm{~nm}$ to $25 \mathrm{~nm}$ thick (corresponding to $0.17-0.24$ mean free path and considering the inelastic mean free path for iron at $200 \mathrm{keV}$ as to 102 $\mathrm{nm}[56])$. Additional TEM and STEM-EDX analyses on the unirradiated and $\mathrm{He}^{2+}$ irradiated samples were performed to detect other irradiation damage features such as clusters or black dots damage but these could not be easily distinguished from defects present before irradiation due to the presence of numerous dislocations in the bainitic structure (see Supplementary File). It has to be noted that at this level of displacement damage, the number density of black dot damage is generally very low compared to that of bubbles[57]. Moreover, since the $\alpha$ value for loops is generally assumed to be $<0.2$ [55] and since the overall hardening due to two sources with similar $\alpha$ values would be $\left(\Delta \sigma_{1}^{2}+\Delta \sigma_{2}^{2}\right)^{0.5}$, the root sum square (RSS) superposition law[55], the contribution to strengthening due to black dot damage was estimated to be minor (see calculations in the Supplementary File). The overall increase in strength $(\Delta \sigma)$ was calculated to be $\sim 790 \mathrm{MPa}$, which is still within the uncertainty limits of the experimental values. Since the increase in yield strength due to helium bubbles alone, calculated with Equation 1, is in good agreement with the yield strength increase measured by microtensile testing shown in Figure 8d, it can be deduced that the helium bubbles were the primary source of hardening.

\section{Discussion}

\subsection{Comparing hardness from nanoindentation with yield strength from}

\section{microtensile tests}

The increase in hardness $(\Delta H)$ from the unirradiated to the $0.6 \mathrm{dpa} \mathrm{He}^{2+}$ irradiated sample was approximately $3.15 \pm 0.34 \mathrm{GPa}$ when data were averaged across the implanted layer depth. It is well 
known that mechanically ground and polished surfaces show an initial increase in strength during nanoindentation[58], therefore, only hardness data obtained at a depth greater than $750 \mathrm{~nm}$ were considered. By averaging the hardness values for depths between $800 \mathrm{~nm}$ and $1800 \mathrm{~nm}$ the $\Delta H$ was calculated to be $3.22 \pm 0.29 \mathrm{GPa}$. The HIP steel investigated in this work presented a non-conventional microstructure for a RPV steel: a mixed ferritic/bainitic microstructure instead of a fully bainitic one. As such, no correlations for the conversion of hardness to change in yield strength were found in the literature. Given that the $0.2 \%$ proof stress and UTS measured by microtensile testing were in good agreement with the standard tensile properties measured on the unirradiated material, it was assumed that the same good agreement existed on the irradiated material. Irradiation hardening from microtensile testing was measured from Figure $8 \mathrm{~d}$ and it was $727.7 \pm 72.5 \mathrm{MPa}$. A relationship between change in nanohardness $\left(\mathrm{H}_{n}\right)$ to change in tensile yield stress for this HIP ferritic/bainitic helium ion irradiated steel could therefore be derived and it is shown in Equation 2:

$$
\Delta \sigma_{y}=226 \times \Delta H_{n}
$$

where $\Delta \sigma_{y}$ is expressed in MPa and was measured by microtensile testing and $\Delta H_{n}$ is expressed in GPa and was measured by nanoindentation equipped with a Berkovich tip.

The correlation derived for this system shown in Equation 2 was formulated using a similar structure to the Rice and Stoller[59] correlation. Rice and Stoller[59] proposed a correlation between nanohardness $\left(\mathrm{H}_{n}\right)$ and tensile yield stress in ferritic and ferritic/martensitic steels with yield stress in the range of 150 to $750 \mathrm{MPa}$, a range that is consistent with the steel used for this study. The Rice and Stoller[59] relationship between tensile yield stress and nanohardness is:

$$
\Delta \sigma_{y}=274 \times \Delta H_{n}
$$

where the yield stress change is expressed in MPa and the nanohardness change in GPa. The parameter obtained from this work and shown in Equation 2 is close to the parameter obtained by Rice and Stoller [59].

Considering a nanohardness change of $3.22 \pm 0.29$ GPa obtained from this work, the increase in yield stress estimated using Rice and Stoller [59] correlation would have been 882.3 $\pm 79.5 \mathrm{MPa}$ which would 
have, however, overestimated the hardening response of this HIP ferritic/bainitic steel. A comparison between $0.2 \%$ proof stress values obtained from micromechanical testing and from nanoindentation using Rice and Stoller [59] equation is shown in Table 4. The error on the $0.2 \%$ proof stress increase was calculated using the error propagation equation:

$$
\delta \sigma=\sqrt{\left(\delta \sigma_{\text {unirradiated }}\right)^{2}+\left(\delta \sigma_{\text {irradiated }}\right)^{2}}
$$

where $\delta \sigma_{\text {unirradiated }}$ represents the $2 \mathrm{SE}$ of the unirradiated yield stress calculated from 4 tests and $\delta \sigma_{\text {irradiated }}$ represents the $2 \mathrm{SE}$ of the irradiated yield stress calculated from 3 tests. The increase of yield stress, $\Delta \sigma_{y}$, was calculated subtracting the yield stress of irradiated with unirradiated specimens.

Table 4 Comparison of $0.2 \%$ proof stresses calculated from nanohardness and from macro and microtensile tests on unirradiated and irradiated samples. N.A. stands for not applicable. $(*)$ The $0.2 \%$ proof stress on the irradiated steel was measured from the averaged microtensile plot of S5, S6 and S7. Errors are shown as 2SE

\begin{tabular}{|c|c|ccc|}
\cline { 2 - 5 } \multicolumn{1}{c|}{} & $\begin{array}{c}\text { Hardness measured at } \\
\text { a depth between } 800 \\
\mathrm{~nm} \text { and } 1800 \mathrm{~nm}\end{array}$ & \multicolumn{3}{|c|}{$\begin{array}{c}\sigma=0.2 \% \text { proof stress } \\
\text { (MPa) }\end{array}$} \\
\cline { 2 - 5 } & CSM mode $(\mathrm{GPa})$ & Standard test & Microtensile test & $\begin{array}{c}\text { Nanoindentation } \\
\text { correlation Eq. 3 [59] }\end{array}$ \\
\hline $\begin{array}{c}\text { Unirradiated } \\
\text { Irradiated } \\
\text { 0.6dpa }\end{array}$ & $2.78 \pm 0.23$ & $456.2 \pm 1$ & $501.6 \pm 56.0$ & N.A. \\
\hline & $6.00 \pm 0.18$ & N.A. & $1229.3 \pm 46\left(^{*}\right)$ & N.A. \\
\hline
\end{tabular}

The correlation from Rice and Stoller[59] developed for ferritic steels overestimated the increase in yield stress observed in this work: $882.3 \pm 79.5 \mathrm{MPa}$ compared to that of $727.7 \pm 72.5 \mathrm{MPa}$ measured by microtensile testing. The most reliable method for measuring irradiation induced strengthening and embrittlement of this HIP SA508 RPV ferritic/bainitic steel was shown here to be microtensile testing.

\subsection{Comparing increase of yield stress between ion and neutron irradiated RPV steels}

The damage induced by helium ion irradiation is certainly different from that by neutrons due to many fundamental differences in the nature of the radiation, including dose rates and, in particular for this 
case, He accumulation. Nevertheless, a comparison of mechanical property degradation from these two types of particles is described here as previous works have reported on neutron irradiation hardening of a RPV steel at similar temperatures and dpa. When comparing the results of Table 4 with hardening of neutron irradiated RPV steels it was noticed that helium ion irradiation induced higher irradiation hardening. The 0.6 dpa RPV steel studied in this work showed approximately $730 \pm 70 \mathrm{MPa}$ increase in $0.2 \%$ proof stress measured from microtensile testing. Other RPV steels irradiated with neutrons at a temperature relevant to this work showed an increase in hardness of approximately $500 \mathrm{MPa}$ for a similar dose received. Farrell et al[60] and Kim et al.[61] reported on A533B RPV steel irradiated up to a dose of $0.89 \mathrm{dpa}$ at a temperature of $60-100{ }^{\circ} \mathrm{C}$ at a fluence of $5.9 \times 10^{20} \mathrm{n} \mathrm{m}^{-2}$ to $5.5 \times 10^{24} \mathrm{n} \mathrm{m}^{-2}$ $(\mathrm{E}>1 \mathrm{MeV})$ in the High Flux Isotope Reactor (HFIR). The 0.89 dpa samples showed a yield stress $(0.2 \%$ proof stress) of $1023 \pm 14 \mathrm{MPa}$ (1SE). The hardening was $526.5 \pm 15 \mathrm{MPa}$ as the unirradiated yield stress was $496.5 \pm 11 \mathrm{MPa}$, which is approximately $200 \mathrm{MPa}$ lower than the hardening reported in this work after linearly interpolating their data to a dose equivalent to $0.6 \mathrm{dpa}$ according to their yield stressdose dependence correlation. The reason for the appreciably greater increase in hardness measured on the 0.6 dpa ion irradiated RPV steel from this work is likely related to the presence of fine helium bubbles/voids implanted in the material as a result of the use of the degrader wheel (see Figure 9). Implanted bubbles alone contributed to $707 \pm 99 \mathrm{MPa}$ increase in yield stress as calculated from the DBH model. The discrepancy in hardening measured in this study can also be related to the approximations used when comparing dpa estimated from SRIM/TRIM simulations to dpa obtained by neutrons flux data[61] and a difference in dpa rates used. Dpa rate was not provided by Farrell et al.[60]. and Kim et al.[61], however, Klueh \& Harries [62] published a displacement dose for HFIR to be $1.1 \times$ $10^{-7} \mathrm{dpa} \mathrm{s}^{-1}$ ( when the reactor is operated at $100 \mathrm{MW}$ ). The dpa rate obtained from this work using helium ions was $1.6 \times 10^{-6} \mathrm{dpa} \mathrm{s}^{-1}$, an order of magnitude larger. Usually, lower dose rates induce higher degree of hardening in ion implanted materials[63,64]. In this work, the larger dpa rate used induced a higher hardening, however, this can be related to the different damage induced by helium ions compared to neutrons as the implanted bubbles contributed to approximately 600-800 MPa increase in yield stress. Another source of variation in hardening behaviour may be related to the material tested: the steel used 
by Farrell et al[60]. and Kim et al.[61] was A533B instead of SA508 grade 3. Both steels are, however, of a tempered bainitic nature with a matrix of bcc ferrite.

\subsection{Comparing microtensile data with macrotensile data}

It is possible that the discrepancy between irradiation hardening measured in this work on $0.6 \mathrm{dpa} \mathrm{He}^{2+}$ room temperature irradiated HIP SA508 grade 3 steel (hardening of $727.7 \pm 72.5 \mathrm{MPa}$ ) with previous works[60,61] reporting on 0.6 dpa neutron irradiated RPV steels (hardening of $\approx 500 \mathrm{MPa}$ ), may be induced by the use of microtensile testing instead of standard macrotensile testing. Micromechanical testing is not yet a conventional method for assessing irradiation hardening and there is the possibility of discrepancies induced by size effects[20,65]. However, it was shown in this work that the microtensile $0.2 \%$ proof stress and UTS were in reasonable agreement (considering uncertainty on microtensile test) with the corresponding bulk values from standard testing when the data obtained from different microtensile tests were combined through averaging. To understand the influence of the number of specimens sampled on the mechanical properties measured by micromechanical testing, the UTS and $0.2 \%$ proof stress for each individual specimen were measured. The individual mechanical properties were then calculated considering 2,3 or 4 samples. In this way it was possible to calculate a sampling-affected value for the UTS and $0.2 \%$ proof stress and compare this to the bulk macrotensile data provided by Rolls-Royce, see Figure 10. The combined pole figure for each sampling configuration is shown to help the reader understand the number of orientations considered for each sampling. 

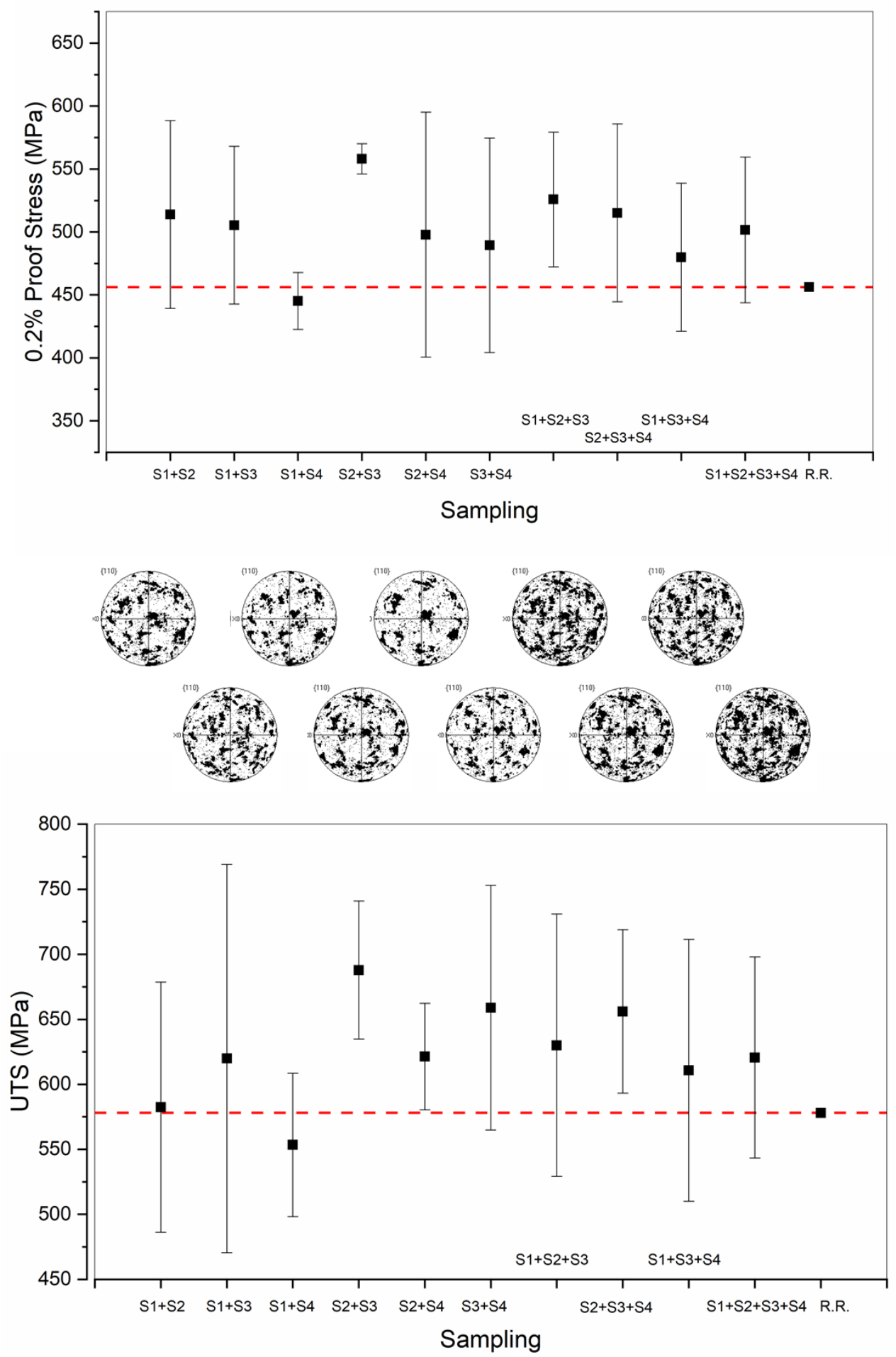

Figure 10 The effect of sampling considering individual microtensile specimen or 2, 3 or 4 microtensile specimens on the UTS and $0.2 \%$ proof stress compared to the bulk UTS and $0.2 \%$ proof stress provided by Rolls-Royce. The bulk UTS and $0.2 \%$ proof stress were calculated on three specimens. Error bars correspond to $2 \mathrm{SE}$.

The mechanical properties (in terms of ultimate tensile stress and $0.2 \%$ proof stress) of the unirradiated samples determined by conventional mechanical testing were within the $95 \%$ confidence interval 
obtained via micromechanical tests when the mechanical properties of several samples were considered. The uncertainty, calculated as $2 \mathrm{SE}$, on the UTS and $0.2 \%$ proof stress mean was respectively $77 \mathrm{MPa}$ and $56 \mathrm{MPa}$ from 4 specimens. These uncertainty values compare very favorably to previous work on microtensile testing of steels manufactured from random locations [66]. By comparing the uncertainties on the averaged UTS and YS from this work and Ajantiwalay et al.[66] work, it was found that in Ajantiwalay et al.[66] the uncertainty on averaged UTS and YS from 4 microtensile specimens, calculated as 2SE, were respectively $188 \mathrm{MPa}$ and $195 \mathrm{MPa}$.

Thus, there is strong evidence that the difference in irradiation hardening measured by microtensile testing is not due to the testing method, but due to an intrinsic difference in the effect of ion irradiation versus neutron irradiation, which was here attributed to the considerable increase in hardness due to helium bubbles implanted in the sample.

\section{Conclusions}

Mechanical properties of a HIP SA508 grade 3 ferritic/bainitic steel were measured, at room temperature, via nanoindentation and in-situ micromechanical testing in both as-received condition and as irradiated with $\mathrm{He}^{2+}$ ions to 0.6 dpa.

1) By averaging stresses at a given strain from four as-received microtensile specimens (gauge volume of approximately $17 \times 5 \times 5 \mu \mathrm{m}^{3}$ ) the measured UTS of $620.6 \pm 77.4 \mathrm{MPa}$ and $0.2 \%$ proof stress of $501.6 \pm 56.0 \mathrm{MPa}$ were in reasonable agreement with the standard bulk macrotensile data of $577.8 \pm$ 2.6 MPa and 456.2 $\pm 1.7 \mathrm{MPa}$ respectively (taking into account uncertainties from microtensile testing which are here reported as $2 \mathrm{SE}$ ).

2) The steel sample irradiated to $0.6 \mathrm{dpa}$ using $\mathrm{He}^{2+}$ ions at room temperature showed a considerable hardening and reduction in ductility measured by microtensile testing corresponding to an increase in $0.2 \%$ proof stress of $727.7 \pm 72.5 \mathrm{MPa}$.

3) The increase in proof stress was higher than what might normally be expected from neutron irradiated steels at similar doses and temperatures $\left(\Delta \sigma_{y} 0.2 \%\right.$ proof stress should be $\sim 500 \mathrm{MPa}$ according to literature). TEM analysis identified the presence of fine bubbles/voids implanted within the irradiated 
layer, and the notably higher irradiation hardening observed was related to the presence of these radiation induced defects. The increment in yield strength from the bubbles calculated using the DBH model was $707 \pm 99 \mathrm{MPa}$ which agrees well with the increase in hardness measured by microtensile testing.

4) The nanohardness of bainite and ferrite was measured on unirradiated and ion irradiated samples and it was determined that the difference was $0.44 \pm 0.15 \mathrm{GPa}$ at $\sim 1 \mu \mathrm{m}$ depth on the unirradiated samples, with ferrite being the softer. Nanoindentation performed in CSM mode on the ion irradiated sample measured an increase in hardness of $3.22 \pm 0.29 \mathrm{GPa}$ considering nanohardness values between $800 \mathrm{~nm}$ and $1800 \mathrm{~nm}$ in depth.

5) A correlation that calculates the change of $0.2 \%$ proof stress with change in nanohardness for this particular type of microstructure, HIP ferritic/bainitic steels helium ion irradiated, was here proposed since in literature no suitable correlation existed.

\section{Acknowledgements}

This work was financially supported by the UK Engineering and Physical Sciences Research Council (EPSRC) through the grant EP/P005101/1 "Linking Microstructure to Neutron Irradiation Defects in Advanced Manufacture of Steels". The authors thank Dr. Nick Riddle at Rolls-Royce Plc for helpful discussions and comments during this work, Colin Hobman from Maintenance Workshop at ANSTO for crafting stubs and holders used for microtensile testing, Dr. Robert Wheeler from MicroTesting Solutions and Rolls-Royce Plc., Derby, UK for providing the material used in this study.

\section{Credit author statement}

C. Gasparrini: investigation, conceptualization, data curation, formal analysis, writing - original draft, visualization; A. Xu: investigation, conceptualization, resources, data curation, writing - review \& editing; K. Short: investigation, resources, data curation; T. Wei: investigation, resources, data curation; J. Davis: resources, T. Palmer: resources, D. Bhattacharyya: investigation, supervision, conceptualization, writing - review \& editing, L.Edwards: supervision, conceptualization, writing - 
review \& editing, M.R.Wenman: conceptualization, supervision, funding acquisition, writing - review \& editing

\section{Data availability}

The datasets generated during and/or analysed during the current study are available from the corresponding author on request.

\section{References}

[1] R.K. Nanstad, G.R. Odette, N. Almirall, J.P. Robertson, W.L. Server, T. Yamamoto, P. Well, Effects of ATR-2 irradiation to high fluence on nine RPV surveillance materials, Oak Ridge Natl. Lab. ORNL/TM-2017/172. (2017) 1-24.

[2] G.R. Odette, On the dominant mechanism of irradiation embrittlement of reactor pressure vessel steels, Scr. Metall. 17 (1983) 1183-1188. https://doi.org/10.1016/0036-9748(83)90280-6.

[3] S. Murakami, A. Miyazaki, M. Mizuno, Modeling of irradiation embrittlement of reactor pressure vessel steels, J. Eng. Mater. Technol. 122 (2000) 60-66. https://doi.org/10.1115/1.482766.

[4] G.R. Odette, G.E. Lucas, Irradiation embrittlement of reactor pressure vessel steels: mechanisms, models, and data correlations., Radiat. Embrittlement Nucl. React. Press. Vessel Steels An Int. Rev. 2 (1986) 206-241. https://doi.org/10.1520/STP23038S.

[5] G.R. Odette, G.E. Lucas, Embrittlement of nuclear reactor pressure vessels, Jom J. Miner. Met. Mater. Soc. 53 (2001) 18-22. https://doi.org/10.1007/s11837-001-0081-0.

[6] J.F. Knott, C.A. English, Views of TAGSI on the principles underlying the assessment of the mechanical properties of irradiated ferritic steel reactor pressure vessels, Int. J. Press. Vessel. Pip. 76 (1999) 891-908. https://doi.org/10.1016/S0308-0161(99)00068-X.

[7] G.R. Odette, G.E. Lucas, Recent progress in understanding reactor pressure vessel steel embrittlement, 1998. https://doi.org/10.1080/10420159808229676. 
[8] M.K. Miller, M.G. Burke, An atom probe field ion microscopy study of neutron-irradiated pressure vessel steels, J. Nucl. Mater. 195 (1992) 68-82. https://doi.org/10.1016/00223115(92)90364-Q.

[9] G.S. Was, Challenges to the use of ion irradiation for emulating reactor irradiation, J. Mater. Res. 30 (2015) 1158-1182. https://doi.org/10.1557/jmr.2015.73.

[10] E.A. Kuleshova, B.A. Gurovich, Z. V. Bukina, A.S. Frolov, D.A. Maltsev, E. V. Krikun, D.A. Zhurko, G.M. Zhuchkov, Mechanisms of radiation embrittlement of VVER-1000 RPV steel at irradiation temperatures of $(50-400)^{\circ} \mathrm{C}, \quad$ J. Nucl. Mater. (2017). https://doi.org/10.1016/j.jnucmat.2017.04.035.

[11] B. Gurovich, E. Kuleshova, Y. Shtrombakh, S. Fedotova, O. Zabusov, K. Prikhodko, D. Zhurko, Evolution of weld metals nanostructure and properties under irradiation and recovery annealing of VVER-type reactors, J. Nucl. Mater. 434 (2013) 72-84. https://doi.org/10.1016/j.jnucmat.2012.11.026.

[12] P.R. Okamoto, L.E. Rehn, Radiation-induced segregation in binary and ternary alloys, J. Nucl. Mater. 83 (1979) 2-23. https://doi.org/10.1016/0022-3115(79)90587-7.

[13] R.S. Nelson, J.A. Hudson, D.J. Mazey, The stability of precipitates in an irradiation environment, J. Nucl. Mater. 44 (1972) 318-330. https://doi.org/10.1016/0022-3115(72)900438.

[14] K.J. Stephenson, G.S. Was, Comparison of the microstructure, deformation and crack initiation behavior of austenitic stainless steel irradiated in-reactor or with protons, J. Nucl. Mater. 456 (2015) 85-98. https://doi.org/10.1016/j.jnucmat.2014.08.021.

[15] D.J. Mazey, Fundamental aspects of high-energy ion-beam simulation techniques and their relevance to fusion materials studies, J. Nucl. Mater. 174 (1990) 196-209. https://doi.org/10.1016/0022-3115(90)90234-E.

[16] G.S. Was, J.T. Busby, T. Allen, E.A. Kenik, A. Jensson, S.M. Bruemmer, J. Gan, A.D. Edwards, 
P.M. Scott, P.L. Andreson, Emulation of neutron irradiation effects with protons: Validation of principle, J. Nucl. Mater. 300 (2002) 198-216. https://doi.org/10.1016/S0022-3115(01)007516.

[17] P. Hosemann, D. Frazer, M. Fratoni, A. Bolind, M.F. Ashby, Materials selection for nuclear applications: Challenges and opportunities, Scr. Mater. 143 (2018) 181-187. https://doi.org/10.1016/j.scriptamat.2017.04.027.

[18] G.E. Lucas, Review of small specimen test techniques for irradiation testing, Metall. Trans. A. 21 (1990) 1105-1119. https://doi.org/10.1007/BF02656531.

[19] D. Kiener, W. Grosinger, G. Dehm, R. Pippan, A further step towards an understanding of sizedependent crystal plasticity: In situ tension experiments of miniaturized single-crystal copper samples, Acta Mater. 56 (2008) 580-592. https://doi.org/10.1016/j.actamat.2007.10.015.

[20] D. Kiener, W. Grosinger, G. Dehm, On the importance of sample compliance in uniaxial microtesting, Scr. Mater. 60 (2009) 148-151. https://doi.org/10.1016/j.scriptamat.2008.09.024.

[21] H.T. Vo, A. Reichardt, D. Frazer, N. Bailey, P. Chou, P. Hosemann, In situ micro-tensile testing on proton beam-irradiated stainless steel, J. Nucl. Mater. 493 (2017) 336-342. https://doi.org/10.1016/j.jnucmat.2017.06.026.

[22] C. Kirchlechner, D. Kiener, C. Motz, S. Labat, N. Vaxelaire, O. Perroud, J.S. Micha, O. Ulrich, O. Thomas, G. Dehm, J. Keckes, Dislocation storage in single slip-oriented Cu micro-tensile samples: New insights via X-ray microdiffraction, Philos. Mag. 91 (2011) 1256-1264. https://doi.org/10.1080/14786431003785639.

[23] K. Fujii, K. Fukuya, Development of micro tensile testing method in an FIB system for evaluating grain boundary strength, Mater. Trans. 52 (2011) 20-24. https://doi.org/10.2320/matertrans.M2010320.

[24] R. Wheeler, A. Pandey, A. Shyam, T. Tan, E. Lara-Curzio, Small scale mechanical characterization of thin foil materials via pin load microtesting, Exp. Mech. 55 (2015) 1375- 
1387. https://doi.org/10.1007/s11340-015-0020-6.

[25] C.J. Szczepanski, S.K. Jha, P.A. Shade, R. Wheeler, J.M. Larsen, Demonstration of an in situ microscale fatigue testing technique on a titanium alloy, Int. J. Fatigue. 57 (2013) 131-139. https://doi.org/10.1016/j.ijfatigue.2012.08.008.

[26] D. Bhattacharyya, R.W. Wheeler, R.P. Harrison, L. Edwards, The observation of slip phenomena in single crystal fe samples during in situ micro-mechanical testing through orientation imaging, Microsc. Microanal. $20 \quad$ (2014) 1060-1069. https://doi.org/10.1017/S1431927614001640.

[27] A. Reichardt, M. Ionescu, J. Davis, L. Edwards, R.P. Harrison, P. Hosemann, D. Bhattacharyya, In situ micro tensile testing of $\mathrm{He}^{+2}$ ion irradiated and implanted single crystal nickel film, Acta Mater. 100 (2015) 147-154. https://doi.org/10.1016/j.actamat.2015.08.028.

[28] A. Xu, M. Saleh, J. Davis, L. Edwards, D. Bhattacharyya, In-situ micro-tensile investigation of strain rate response along $\langle 100\rangle$ and $\langle 110\rangle$ directions in single crystal nickel, Int. J. Plast. 106 (2018) 129-144. https://doi.org/10.1016/j.ijplas.2018.03.005.

[29] A. Xu, T. Wei, D. Bhattacharyya, The effect of strain rate and orientation on He ion irradiated Ni single crystals - An in situ micro-tensile study, Int. J. Plast. 126 (2020) 102627. https://doi.org/10.1016/j.ijplas.2019.11.006.

[30] P.A. Shade, S.L. Kim, R. Wheeler, M.D. Uchic, Stencil mask methodology for the parallelized production of microscale mechanical test samples, Rev. Sci. Instrum. 83 (2012). https://doi.org/10.1063/1.4720944.

[31] Y.S. Choi, M.A. Groeber, P.A. Shade, T.J. Turner, J.C. Schuren, D.M. Dimiduk, M.D. Uchic, A.D. Rollett, Crystal plasticity finite element method simulations for a polycrystalline Ni microspecimen deformed in tension, Metall. Mater. Trans. A. 45 (2014) 6352-6359. https://doi.org/10.1007/s11661-014-2556-y.

[32] A.D. Smith, J. Donoghue, A. Garner, B. Winiarski, E. Bousser, J. Carr, J. Behnsen, T.L. Burnett, 
R. Wheeler, K. Wilford, P.J. Withers, M. Preuss, On the application of Xe+ plasma FIB for micro-fabrication of small-scale tensile specimens, Exp. Mech. 59 (2019) 1113-1125. https://doi.org/10.1007/s11340-019-00528-w.

[33] M. Smolka, C. Motz, T. Detzel, W. Robl, T. Griesser, A. Wimmer, G. Dehm, Novel temperature dependent tensile test of freestanding copper thin film structures, Rev. Sci. Instrum. 83 (2012). https://doi.org/10.1063/1.4725529.

[34] J.F. Ziegler, M.D. Ziegler, J.P. Biersack, SRIM - The stopping and range of ions in matter (2010), Nucl. Instruments Methods Phys. Res. Sect. B Beam Interact. with Mater. Atoms. 268 (2010) 1818-1823. https://doi.org/10.1016/j.nimb.2010.02.091.

[35] R.E. Stoller, M.B. Toloczko, G.S. Was, A.G. Certain, S. Dwaraknath, F.A. Garner, On the use of SRIM for computing radiation damage exposure, Nucl. Instruments Methods Phys. Res. Sect. B Beam Interact. with Mater. Atoms. $310 \quad$ (2013) 75-80. https://doi.org/10.1016/j.nimb.2013.05.008.

[36] T. Wei, H. Zhu, M. Ionescu, P. Dayal, J. Davis, D. Carr, R. Harrison, L. Edwards, Radiation effects on microstructure and hardness of a titanium aluminide alloy irradiated by helium ions at room and elevated temperatures, J. Nucl. Mater. 459 (2015) 284-290. https://doi.org/10.1016/j.jnucmat.2015.01.043.

[37] T. Wei, A. Xu, H. Zhu, M. Ionescu, D. Bhattacharyya, In situ micro-compression testing of He2+ ion irradiated titanium aluminide, Nucl. Instruments Methods Phys. Res. Sect. B Beam Interact. with Mater. Atoms. 409 (2017) 288-292. https://doi.org/10.1016/j.nimb.2017.04.042.

[38] W. Hu, L. Guo, J. Chen, F. Luo, T. Li, Y. Ren, J. Suo, F. Yang, Synergistic effect of helium and hydrogen for bubble swelling in reduced-activation ferritic/martensitic steel under sequential helium and hydrogen irradiation at different temperatures, Fusion Eng. Des. 89 (2014) 324-328. https://doi.org/10.1016/j.fusengdes.2014.02.033.

[39] S. Chen, Y. Wang, N. Hashimoto, S. Ohnuki, Post-irradiation annealing behavior of helium in 
irradiated Fe and ferritic-martensitic steels, Nucl. Mater. Energy. 15 (2018) 203-207. https://doi.org/10.1016/j.nme.2018.04.012.

[40] J.J.H. Lim, J.M. Hyde, S. Lozano-Perez, C.R.M. Grovenor, Microstructural characterization of irradiation-induced MnNi-rich solute cluster in highly neutron-irradiated MnNiMo alloyed weld metals, Eff. Radiat. Nucl. Mater. 26th Vol. 57 (2014) 57-73. https://doi.org/10.1520/STP157220130120.

[41] J. Liu, H. Huang, J. Gao, Z. Zhu, Y. Li, Defects evolution and hardening in the Hastelloy N alloy by subsequent $\mathrm{Xe}$ and $\mathrm{He}$ ions irradiation, J. Nucl. Mater. 517 (2019) 328-336. https://doi.org/10.1016/j.jnucmat.2019.02.022.

[42] C.A. Schneider, W.S. Rasband, K.W. Eliceiri, NIH Image to ImageJ: 25 years of image analysis, Nat. Methods. 9 (2012) 671-675. https://doi.org/10.1038/nmeth.2089.

[43] J. Schindelin, I. Arganda-Carreras, E. Frise, V. Kaynig, M. Longair, T. Pietzsch, S. Preibisch, C. Rueden, S. Saalfeld, B. Schmid, J.Y. Tinevez, D.J. White, V. Hartenstein, K. Eliceiri, P. Tomancak, A. Cardona, Fiji: An open-source platform for biological-image analysis, Nat. Methods. 9 (2012) 676-682. https://doi.org/10.1038/nmeth.2019.

[44] J.Y. Kang, S.J. Park, M.B. Moon, Phase analysis on dual-phase steel using band slope of electron backscatter diffraction pattern, Microsc. Microanal. 19 (2013) 13-16. https://doi.org/10.1017/S1431927613012233.

[45] S. Zaefferer, P. Romano, F. Friedel, EBSD as a tool to identify and quantify bainite and ferrite in low-alloyed Al-TRIP steels, J. Microsc. 230 (2008) 499-508. https://doi.org/10.1111/j.13652818.2008.02010.x.

[46] M. Saleh, A. Xu, C. Hurt, M. Ionescu, J. Daniels, P. Munroe, L. Edwards, D. Bhattacharyya, Oblique cross-section nanoindentation for determining the hardness change in ion-irradiated steel, Int. J. Plast. 112 (2019) 242-256. https://doi.org/10.1016/j.ijplas.2018.08.015.

[47] Y.H. Zhao, Y.Z. Guo, Q. Wei, A.M. Dangelewicz, C. Xu, Y.T. Zhu, T.G. Langdon, Y.Z. Zhou, 
E.J. Lavernia, Influence of specimen dimensions on the tensile behavior of ultrafine-grained $\mathrm{Cu}$, Scr. Mater. 59 (2008) 627-630. https://doi.org/10.1016/j.scriptamat.2008.05.031.

[48] Y.H. Zhao, Y.Z. Guo, Q. Wei, T.D. Topping, A.M. Dangelewicz, Y.T. Zhu, T.G. Langdon, E.J. Lavernia, Influence of specimen dimensions and strain measurement methods on tensile stress$\begin{array}{llllllll}\text { strain } & \text { curves, } & \text { Mater. } & \text { Sci. } & \text { Eng. } & \text { A. } 525 & \text { (2009) }\end{array}$ https://doi.org/10.1016/j.msea.2009.06.031.

[49] J.E. Inglesfield, J.B. Pendry, Energy of helium dissolved in metals, Philos. Mag. 34 (1976) 205215. https://doi.org/10.1080/14786437608221936.

[50] K. Farrell, Experimental effects of helium on cavity formation during irradiation —a review, Radiat. Eff. 53 (1980) 175-194. https://doi.org/10.1080/00337578008207114.

[51] M. Roldán, P. Fernández, J. Rams, D. Jiménez-Rey, E. Materna-Morris, M. Klimenkov, Comparative study of helium effects on EU-ODS EUROFER and EUROFER97 by nanoindentation and TEM, J. Nucl. Mater. $460 \quad$ (2015) 226-234. https://doi.org/10.1016/j.jnucmat.2015.02.025.

[52] C.H. Su, C.H. Zhang, Y.T. Yang, Z.N. Ding, Y.G. Chen, A. Kimura, Hardening of an ODS Ferritic Steel after Helium Implantation and Thermal Annealing, Chinese Phys. Lett. 35 (2018). https://doi.org/10.1088/0256-307X/35/5/056102.

[53] G.E. Lucas, The evolution of mechanical property change in irradiated austenitic stainless steels, J. Nucl. Mater. 206 (1993) 287-305. https://doi.org/10.1016/0022-3115(93)90129-M.

[54] R.E. Stoller, S.J. Zinkle, On the relationship between uniaxial yield strength and resolved shear stress in polycrystalline materials, J. Nucl. Mater. 283-287 (2000) 349-352. https://doi.org/10.1016/S0022-3115(00)00378-0.

[55] G.S. Was, Chapter 12 Irradiation hardening and deformation, in: Fundam. Radiat. Mater. Sci. Met. Alloy. Second Ed., 2016: pp. 669-733.

[56] K. Iakoubovskii, K. Mitsuishi, Y. Nakayama, K. Furuya, Mean free path of inelastic electron 
scattering in elemental solids and oxides using transmission electron microscopy: Atomic number dependent oscillatory behavior, Phys. Rev. B - Condens. Matter Mater. Phys. 77 (2008) 1-7. https://doi.org/10.1103/PhysRevB.77.104102.

[57] P. Dayal, D. Bhattacharyya, W.M. Mook, E.G. Fu, Y.-Q. Wang, D.G. Carr, O. Anderoglu, N.A. Mara, A. Misra, R.P. Harrison, L. Edwards, Effect of double ion implantation and irradiation by Ar and He ions on nano-indentation hardness of metallic alloys, J. Nucl. Mater. 438 (2013) 108115. https://doi.org/10.1016/j.jnucmat.2013.02.078.

[58] F. Pöhl, S. Huth, W. Theisen, Detection of the indentation-size-effect (ISE) and surface hardening by analysis of the loading curvature C, Int. J. Solids Struct. 84 (2016) 160-166. https://doi.org/10.1016/j.ijsolstr.2016.01.024.

[59] P.M. Rice, R.E. Stoller, Correlation of nanoindentation and conventional mechanical property measurements, Fundam. Nanoindentation Nanotribology II, Symp. Q, MRS Proc. 649 (2000) Q7.11. https://doi.org/10.1557/PROC-649-Q7.11.

[60] K. Farrell, T.S. Byun, N. Hashimoto, Deformation mode maps for tensile deformation of neutron-irradiated structural alloys, J. Nucl. Mater. 335 (2004) 471-486. https://doi.org/10.1016/j.jnucmat.2004.08.006.

[61] J.W. Kim, T.S. Byun, Analysis of necking deformation and fracture characteristics of irradiated A533B RPV steel, Nucl. Eng. Technol. $44 \quad$ (2012) 953-960. https://doi.org/10.5516/NET.07.2012.012.

[62] R.L. Klueh, D.R. Harries, High-Chromium Ferritic and Martensitic Steels for Nuclear Applications, ASTM International, 100 Barr Harbor Drive, PO Box C700, West Conshohocken, PA 19428-2959, 2001. https://doi.org/10.1520/MONO3-EB.

[63] K. Fujii, K. Fukuya, T. Hojo, Effects of dose rate change under irradiation on hardening and microstructural evolution in A533B steel, J. Nucl. Sci. Technol. 50 (2013) 160-168. https://doi.org/10.1080/00223131.2013.757465. 
[64] C.D. Hardie, C.A. Williams, S. Xu, S.G. Roberts, Effects of irradiation temperature and dose rate on the mechanical properties of self-ion implanted Fe and Fe-Cr alloys, J. Nucl. Mater. 439 (2013) 33-40. https://doi.org/10.1016/j.jnucmat.2013.03.052.

[65] L. Farbaniec, H. Couque, G. Dirras, Size effects in micro-tensile testing of high purity polycrystalline nickel, Int. J. Eng. Sci. $119 \quad$ (2017) 192-204. https://doi.org/10.1016/j.ijengsci.2017.06.016.

[66] T. Ajantiwalay, H. Vo, R. Finkelstein, P. Hosemann, A. Aitkaliyeva, Towards Bridging the Experimental Length-Scale Gap for Tensile Tests on Structural Materials: Lessons Learned from an Initial Assessment of Microtensile Tests and the Path Forward, JOM. 72 (2020) 113-122. https://doi.org/10.1007/s11837-019-03897-8. 